\title{
Synthesis of Tetracyclic Quinazolinones Using a Visible-Light-Promoted Radical Cascade Approach
}

\author{
Yue-Yue Han, Heng Jiang, Ruzhi Wang and Shouyun Yu*
}

State Key Laboratory of Analytical Chemistry for Life Science, School of Chemistry and Chemical Engineering, Nanjing University,

Nanjing 210023, China.

*E-mail: yushouyun@nju.edu.cn 


\section{Contents}

1. Luminescence quenching of $\operatorname{Ir}(\mathrm{ppy})_{3}$ by compound DIPEA ...... S3

2. Copies of NMR spectra for all compounds................................. S5 


\section{Luminescence quenching of $\operatorname{Ir}(\mathrm{ppy})_{3}$ by compound DIPEA.}

A Hitachi F-7000 fluoresence spectrometer was used to record the emission intensities. All the solutions were excited at $375 \mathrm{~nm}$ and the emission intensity at $513 \mathrm{~nm}$ was observed. $\mathrm{MeCN}$ was degassed with a stream of $\mathrm{N}_{2}$ for $30 \mathrm{~min}$. In a typical experiment, the emission spectrum of a $5 \times 10^{-5} \mathrm{M}$ solution of $\operatorname{Ir}(\mathrm{ppy}){ }_{3}$ in $\mathrm{MeCN}$ was collected. Then, appropriate amount of quencher was added to the measured solution in a quartz cuvette and the emission spectrum of the sample was collected. $\mathrm{I}_{0}$ and I represent the intensities of the emission in the absence and presence of the quencher at $513 \mathrm{~nm}$.
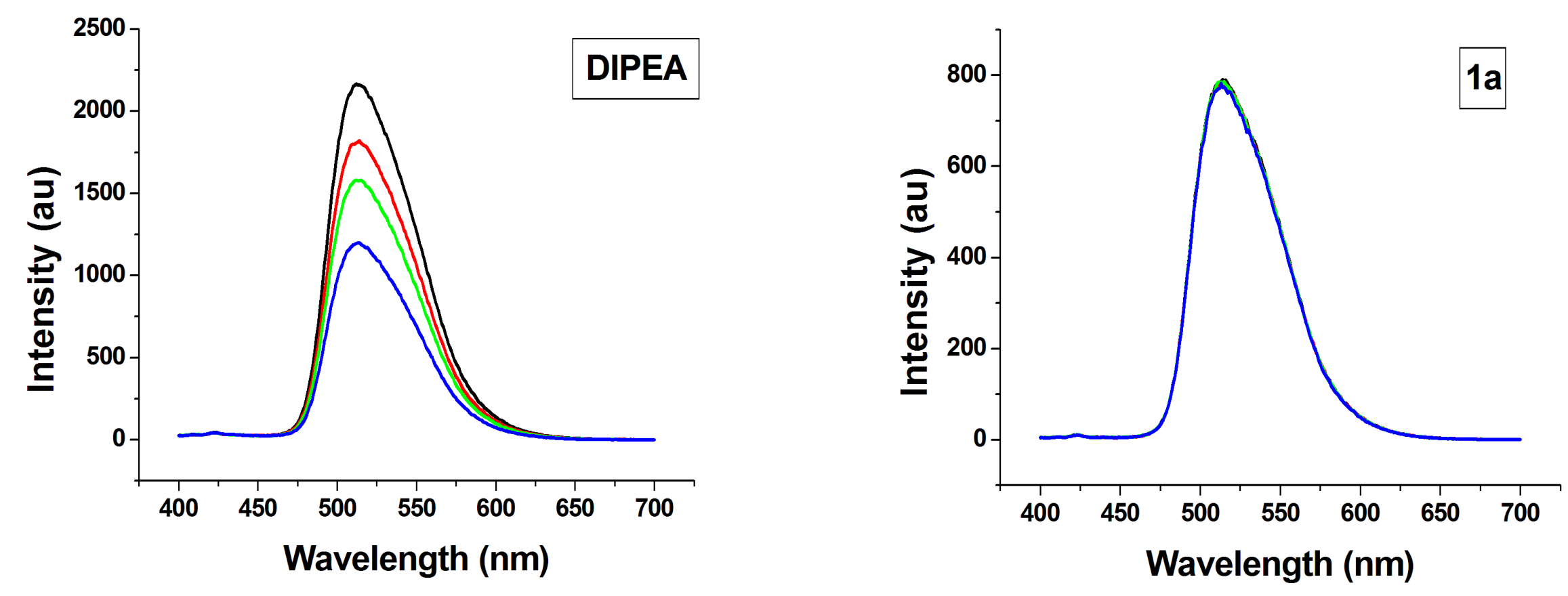




$\mathbf{Y}=\mathbf{A}+\mathbf{B} * \mathbf{X}$

\begin{tabular}{lll} 
Parameter & Value & Error \\
\hline A & 0.95299 & 0.08025 \\
B & 1291.59866 & 214.48513
\end{tabular}

$\begin{array}{llll}\text { R } & \text { SD } & \text { N } & \text { P } \\ -0.97351 & \text { G. } 69592 & 4 & \text { 0. } 02649\end{array}$

$\mathbf{Y}=\mathbf{A}+\mathbf{B} * \mathbf{X}$

\begin{tabular}{|c|c|c|c|}
\hline Parameter & Value & Error & \\
\hline A & 1.00025 & $5.1189 \mathrm{E}-4$ & \\
\hline B & 3.06515 & 0.54723 & \\
\hline $\mathbf{R}$ & SD & $\mathbf{N}$ & $\mathbf{P}$ \\
\hline อ. 96957 & $6.11825 \mathrm{E}-4$ & 4 & 0. 03043 \\
\hline
\end{tabular}


2. Copies of NMR spectra for all compounds.

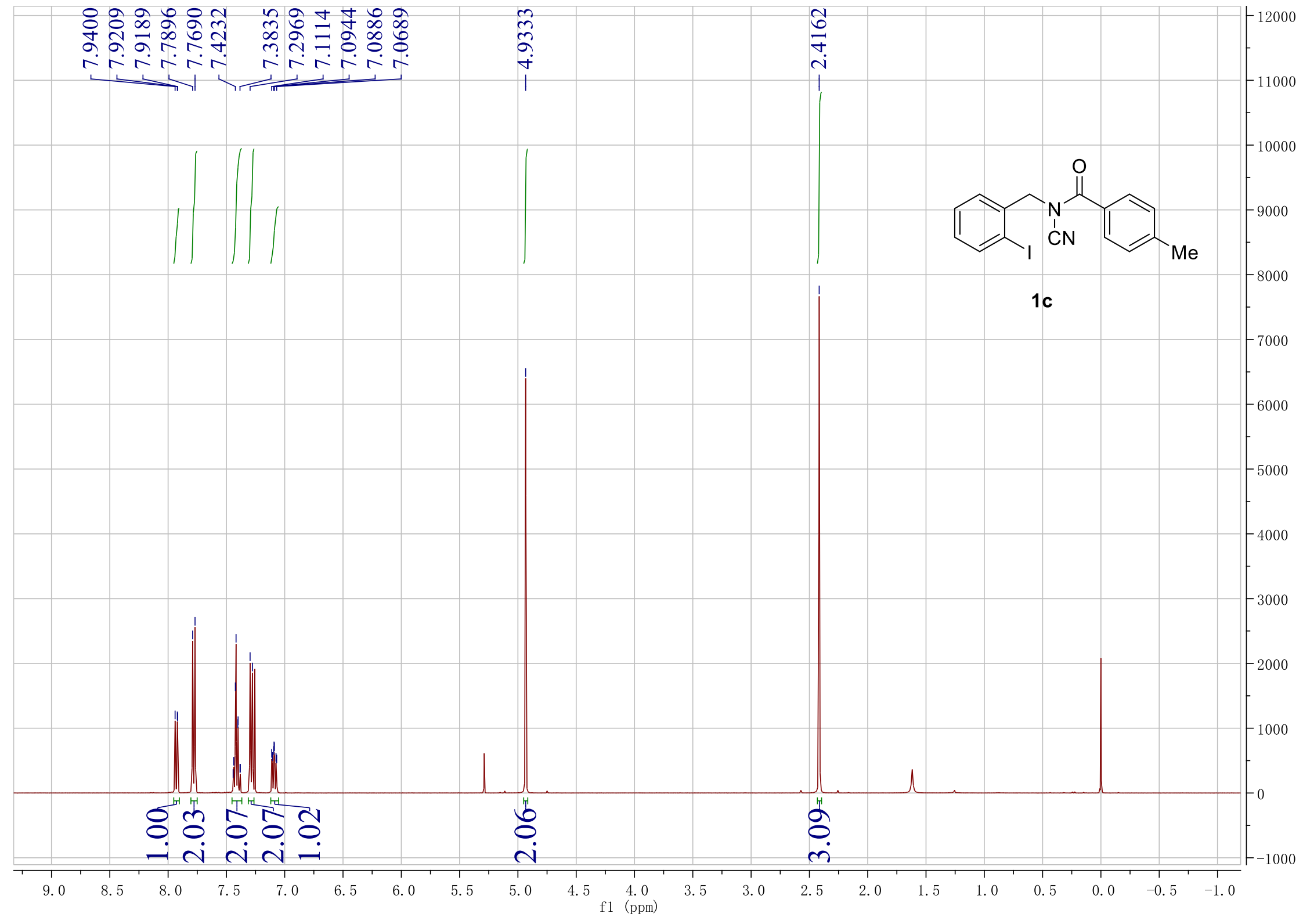




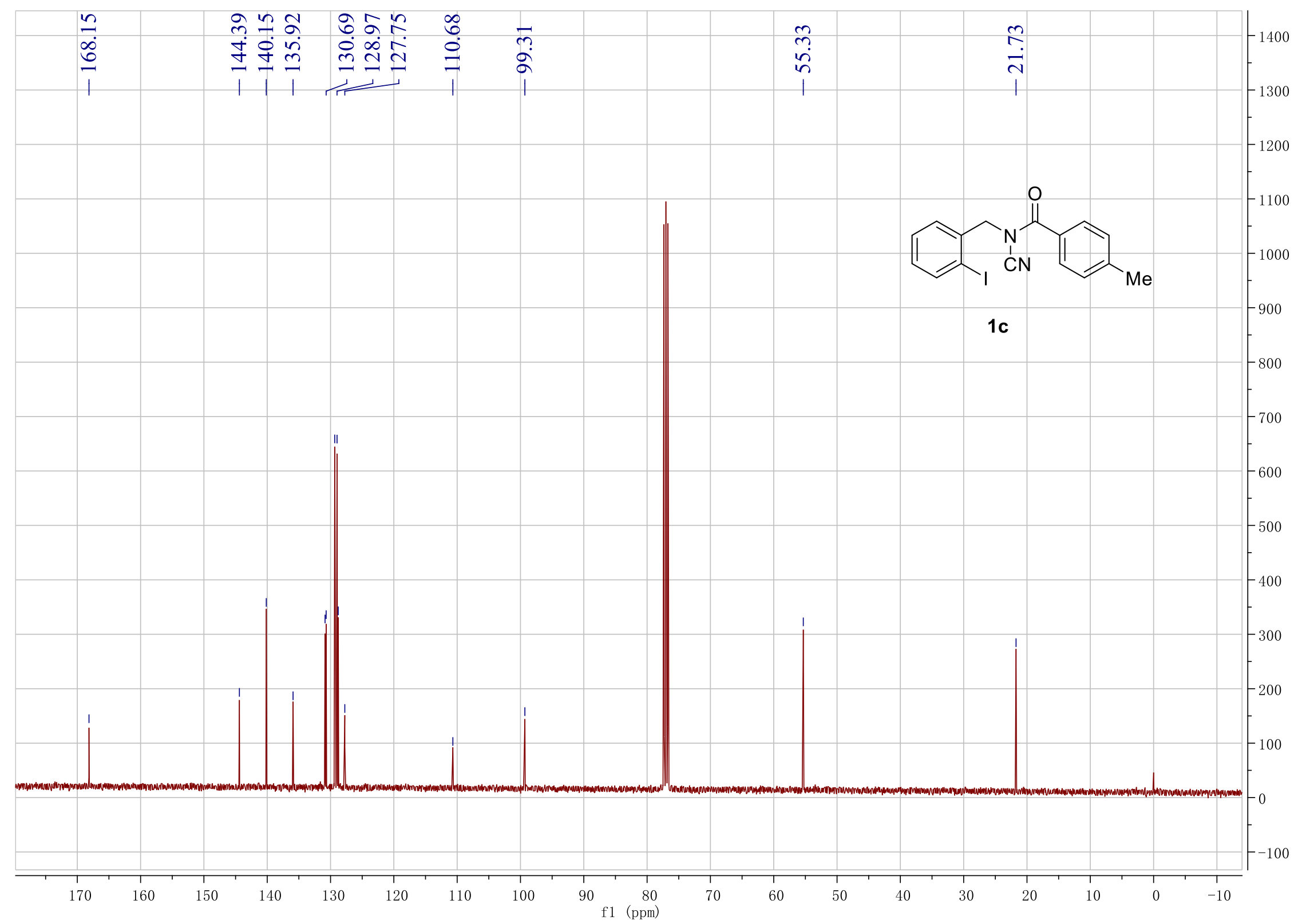









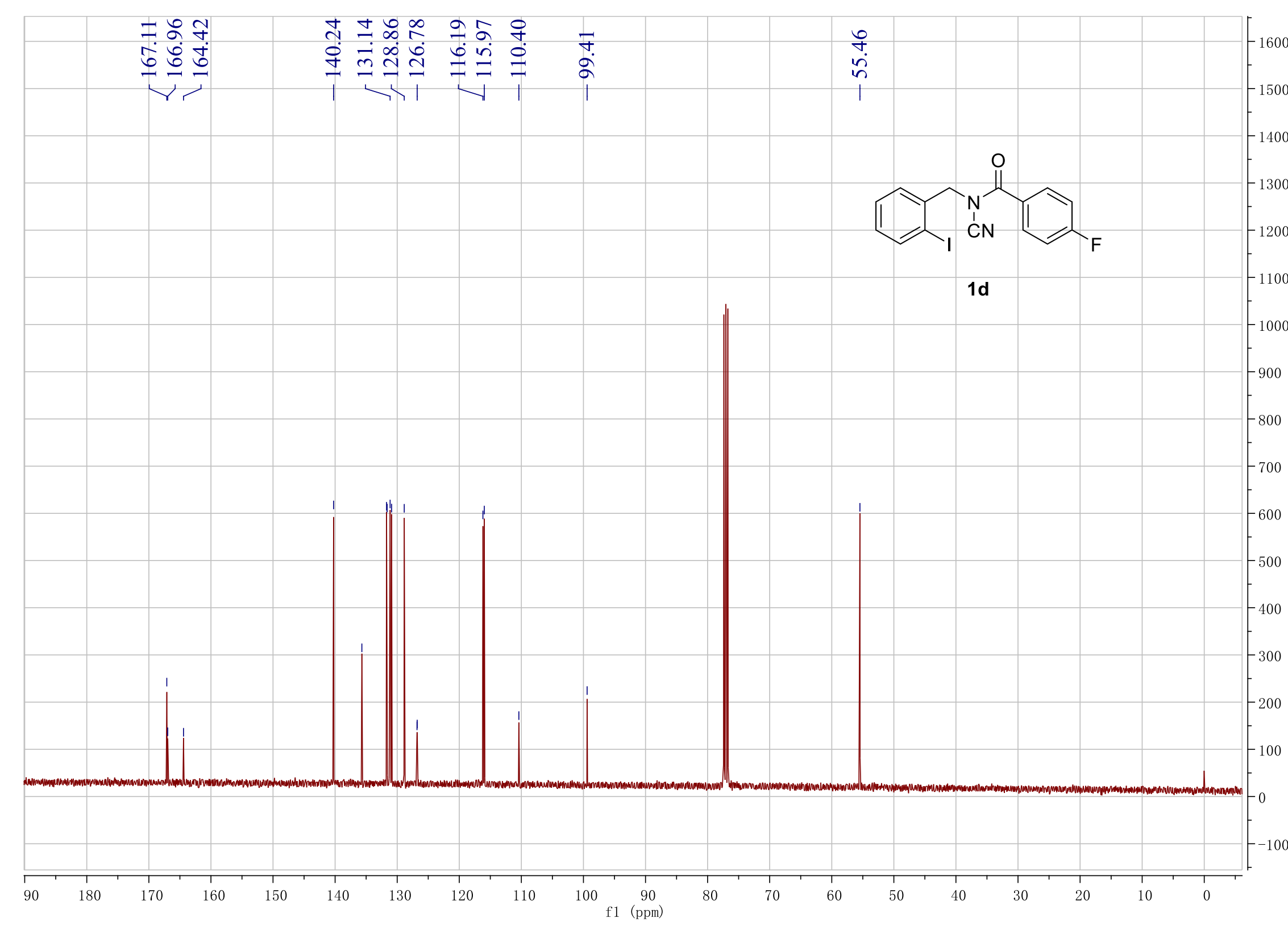




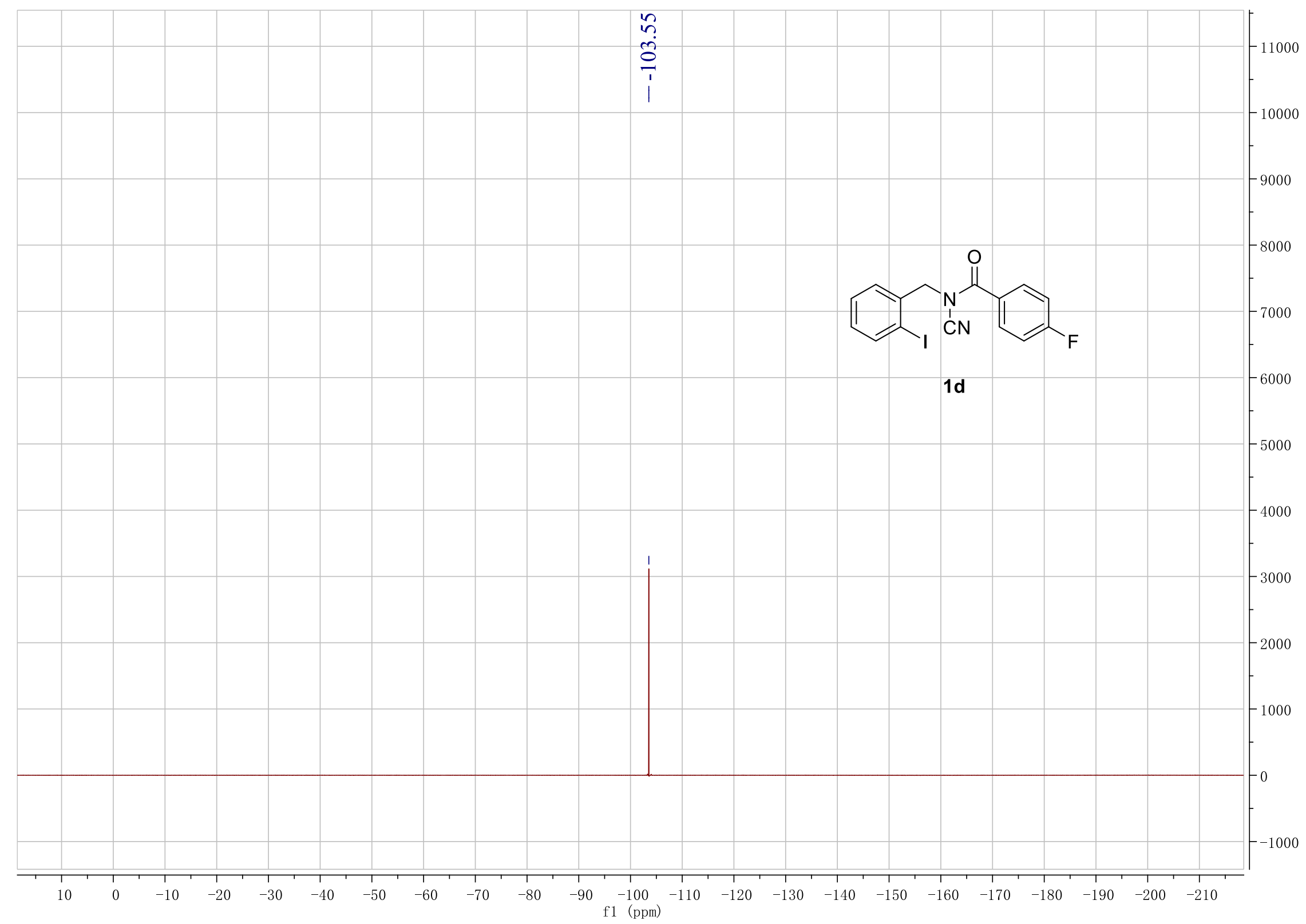




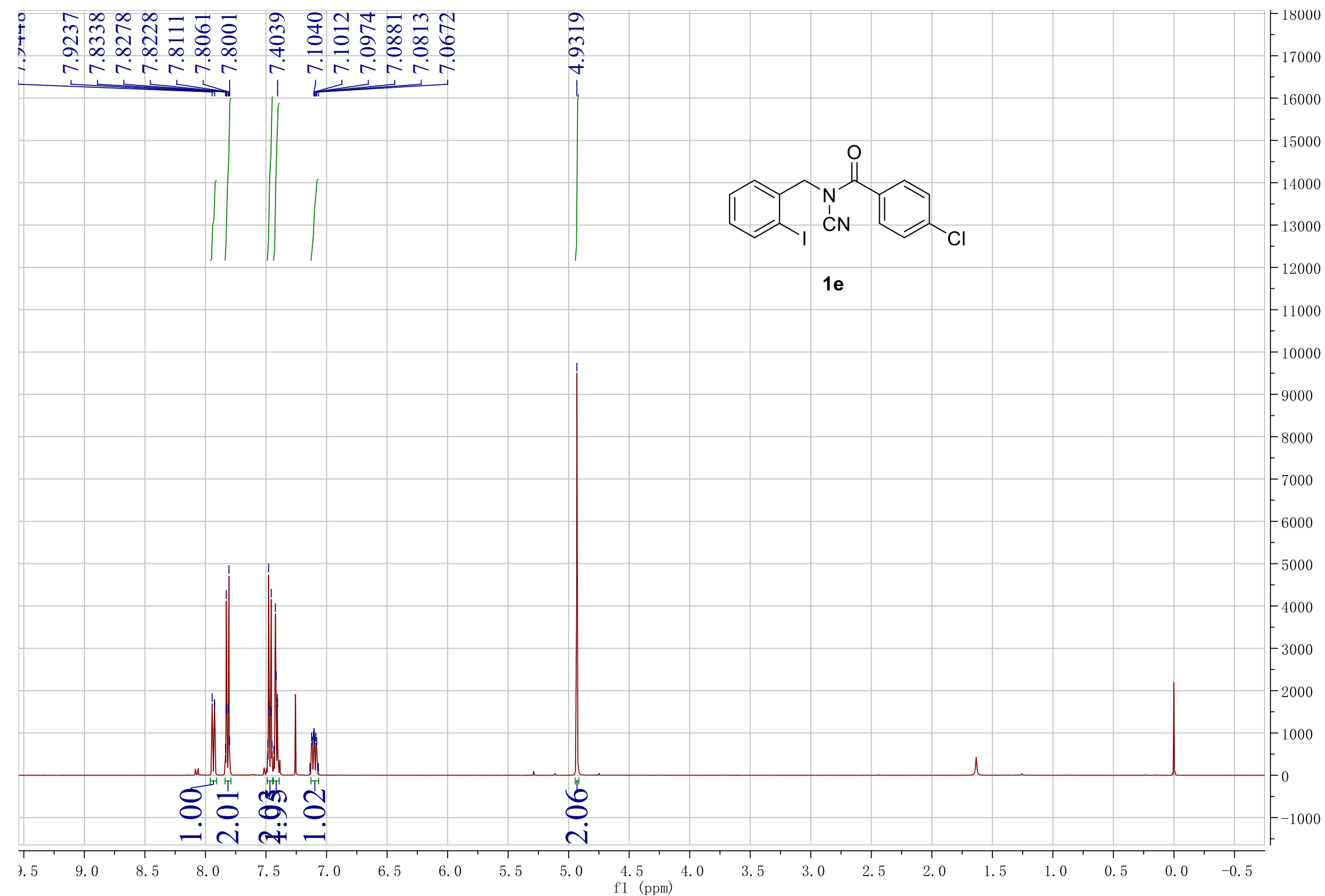




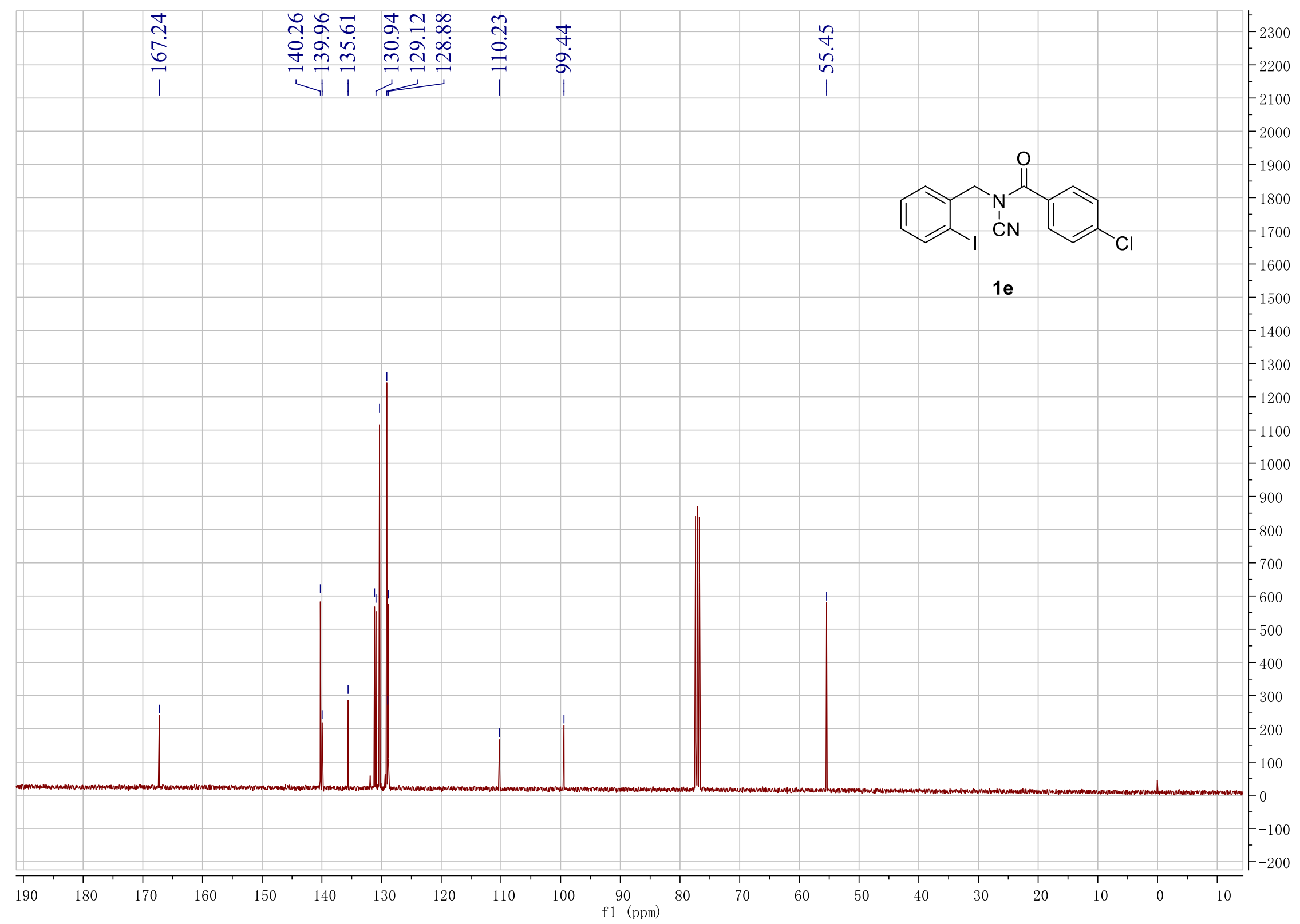




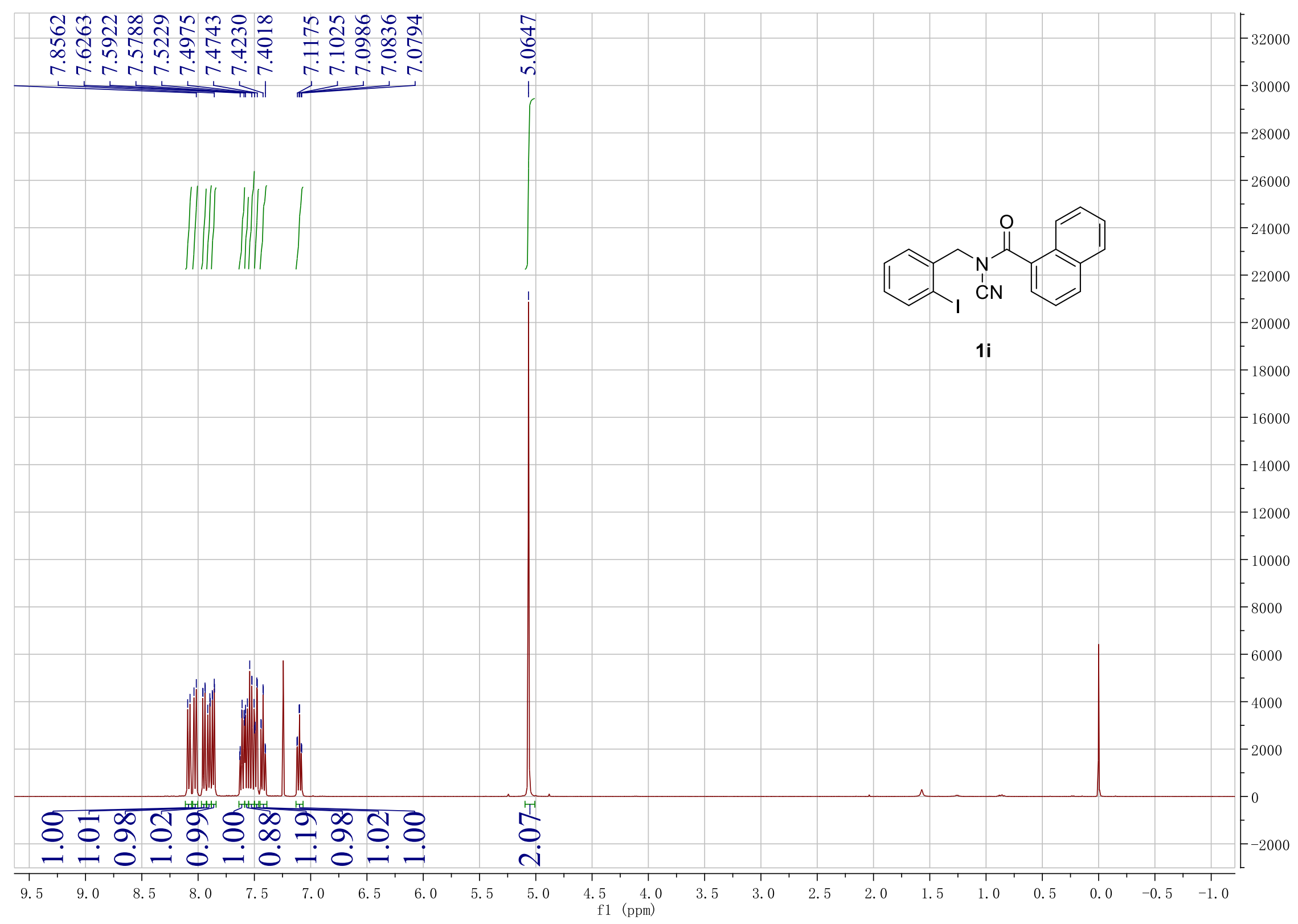




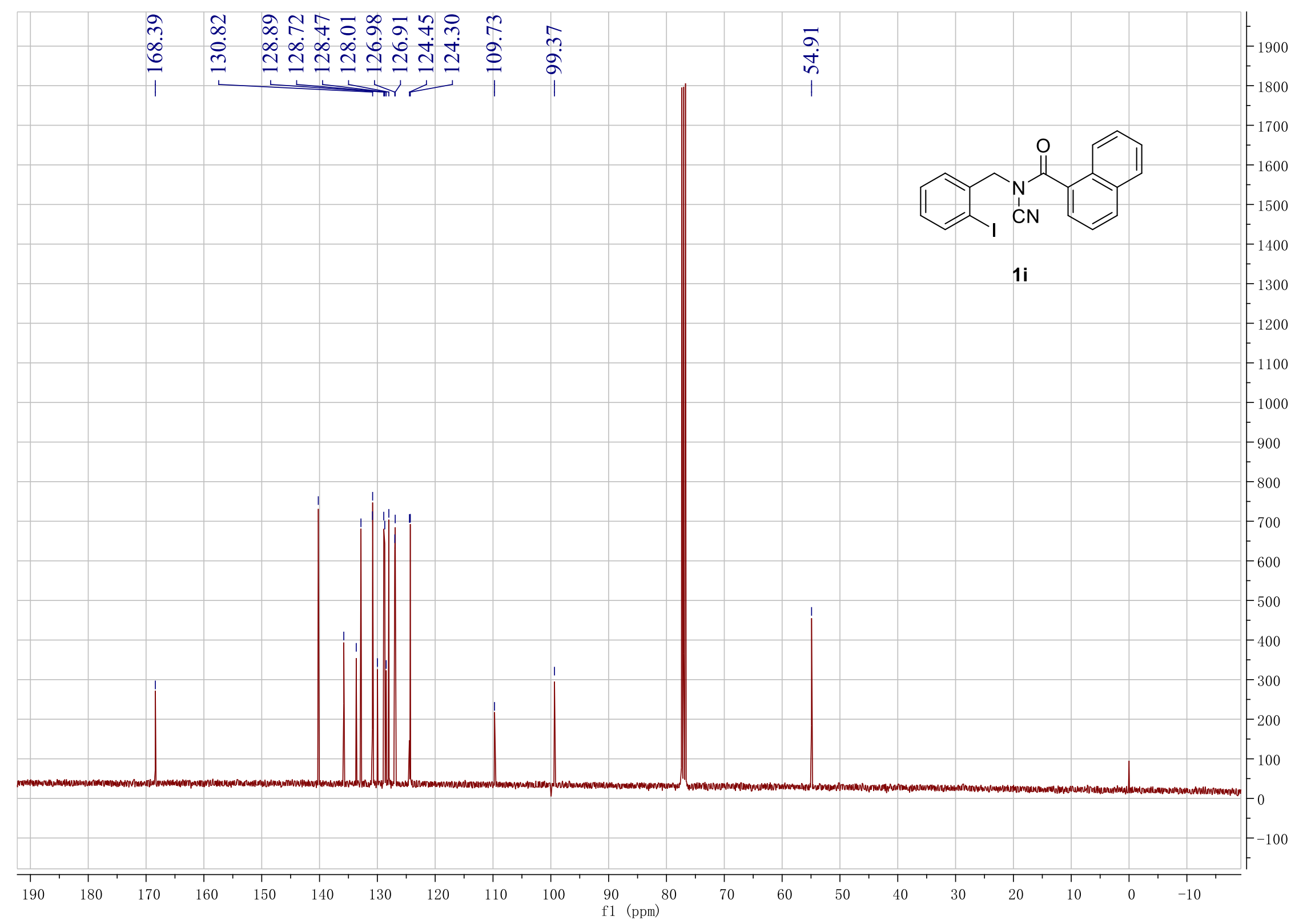




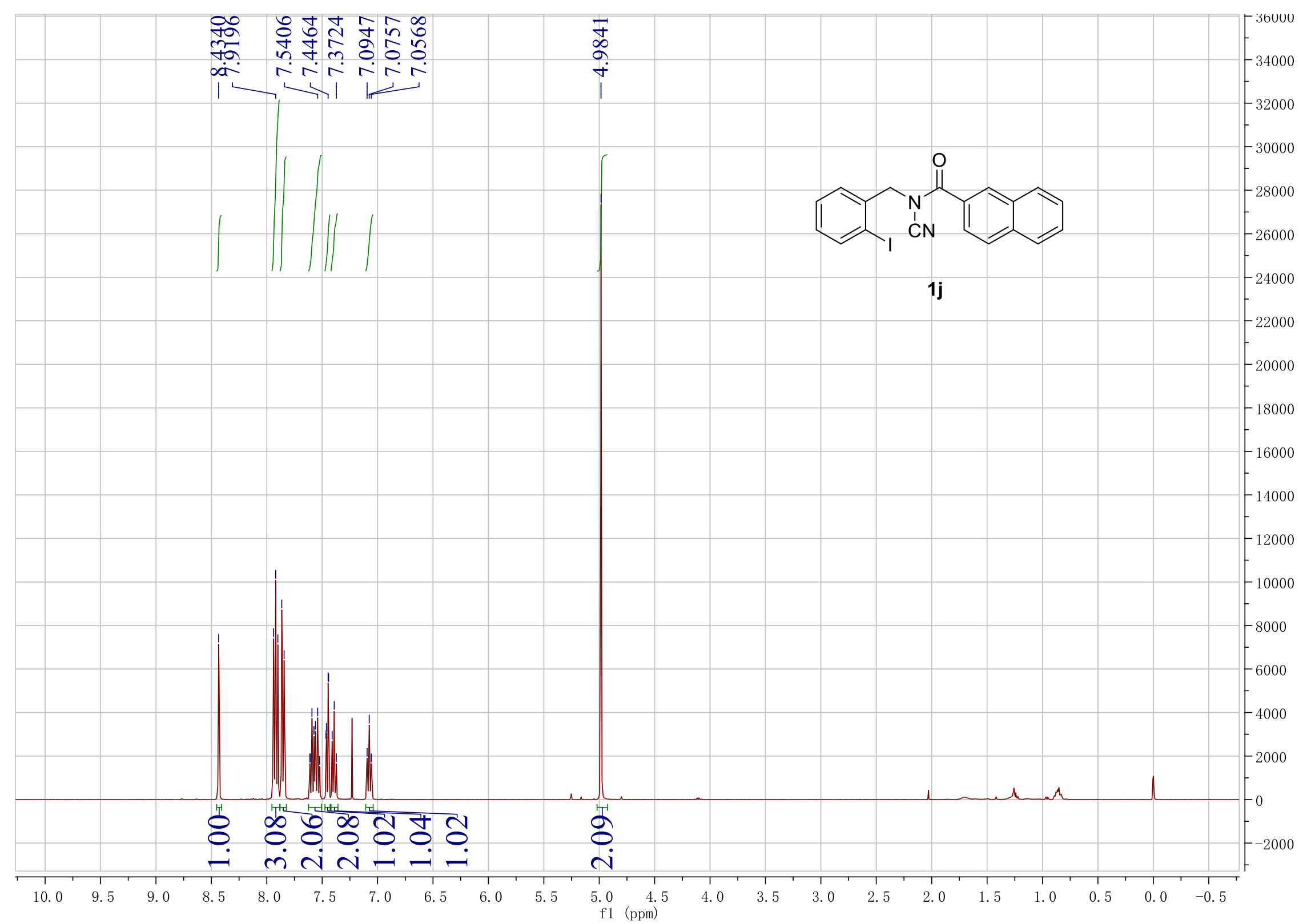




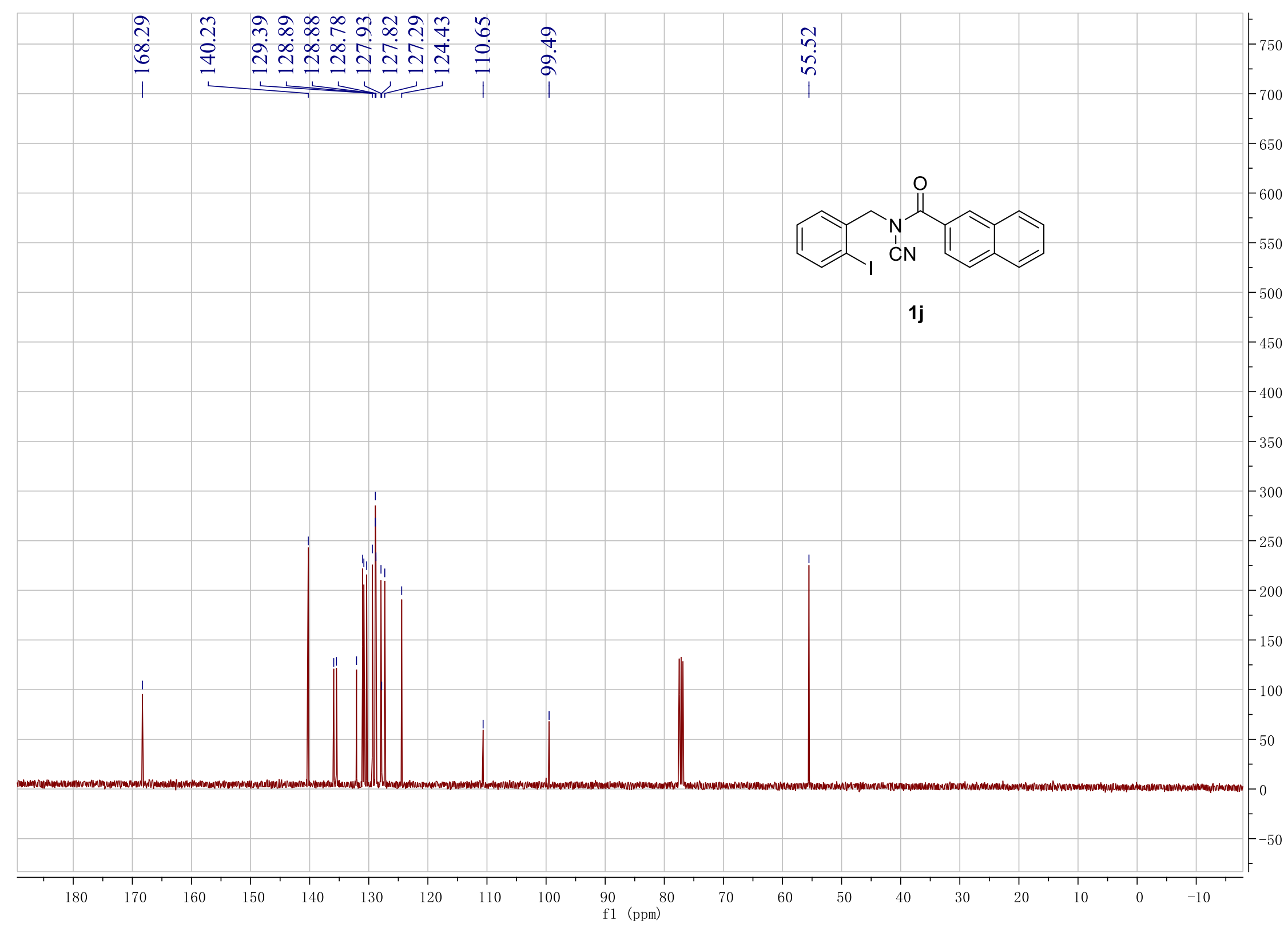




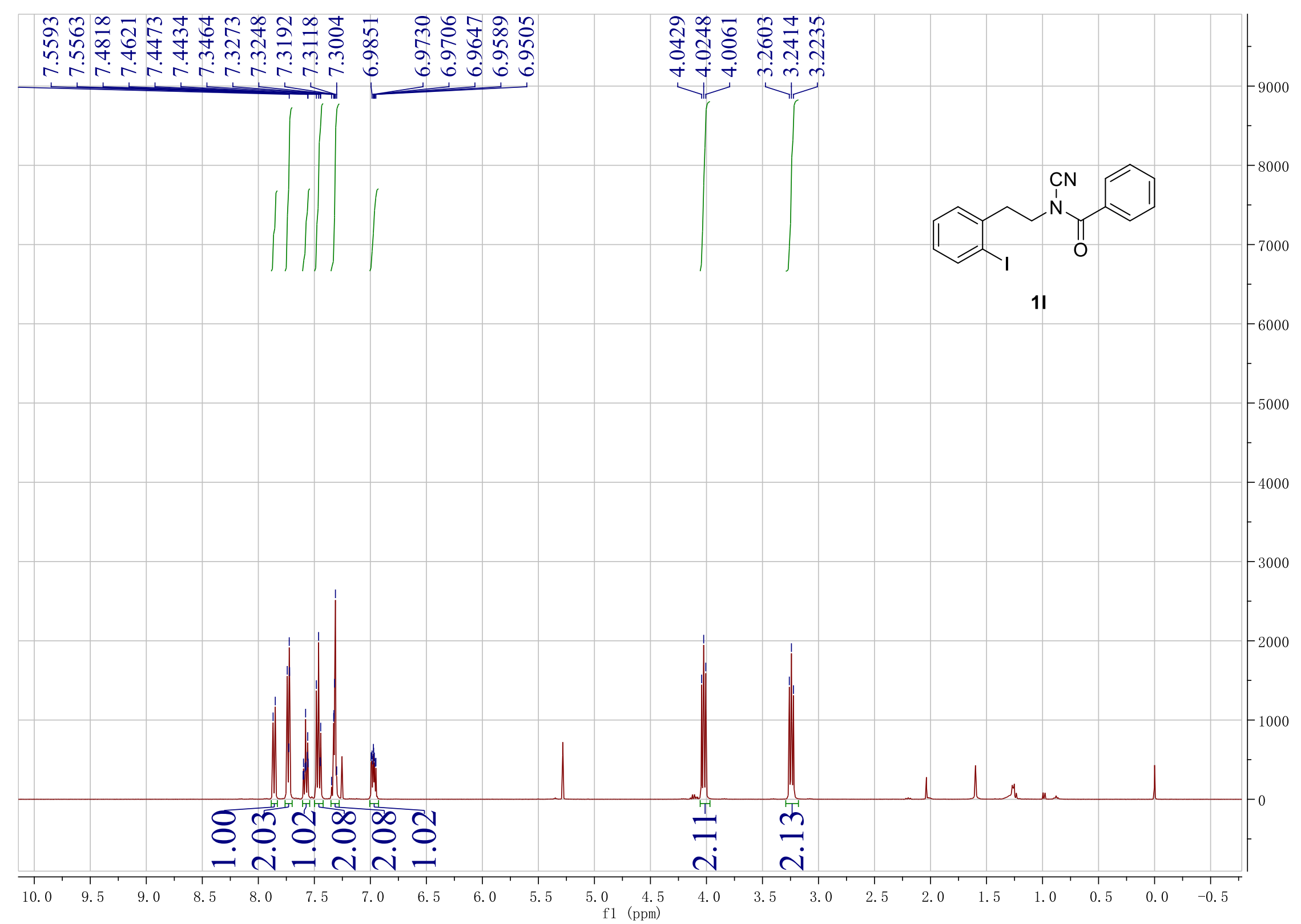




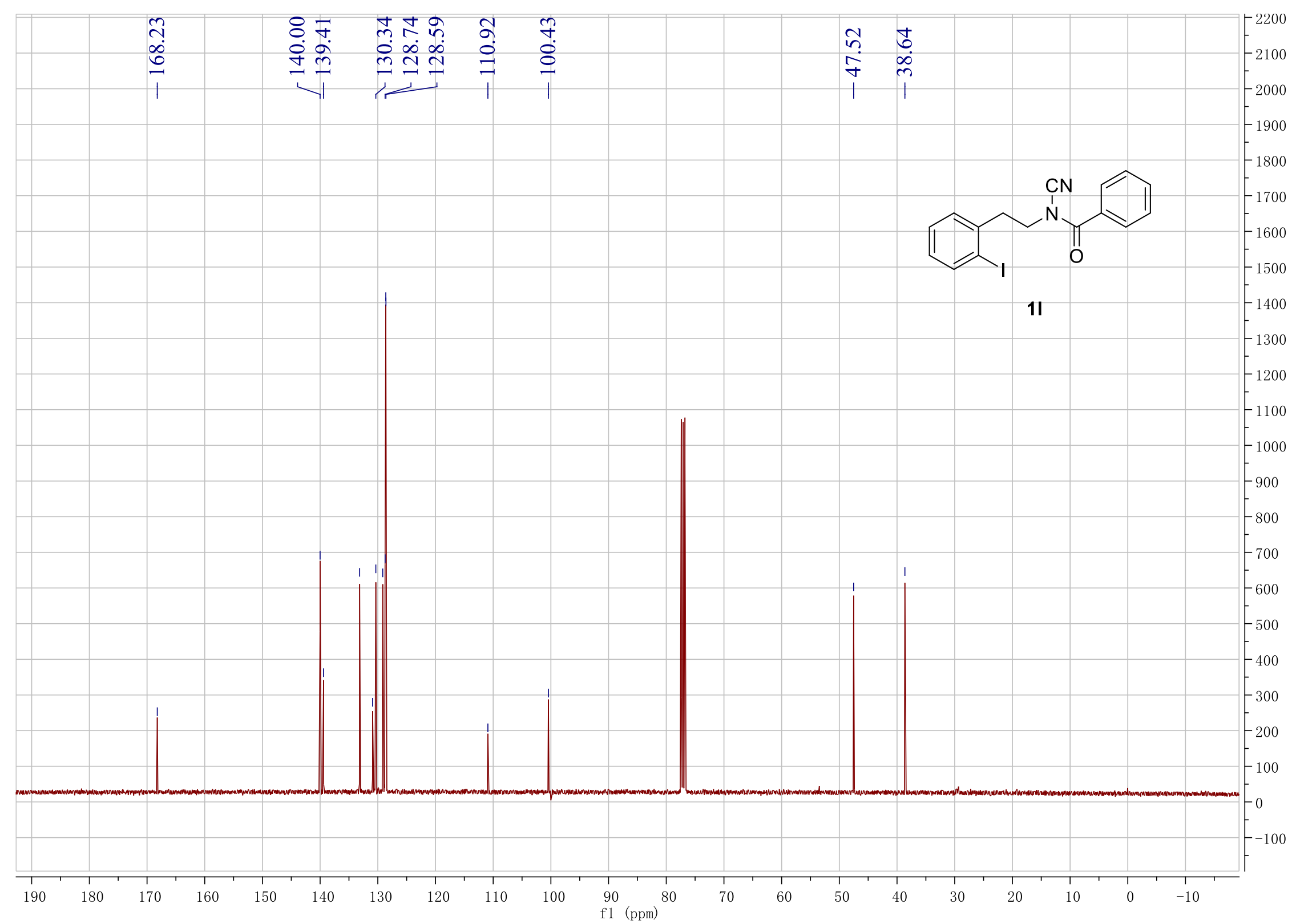




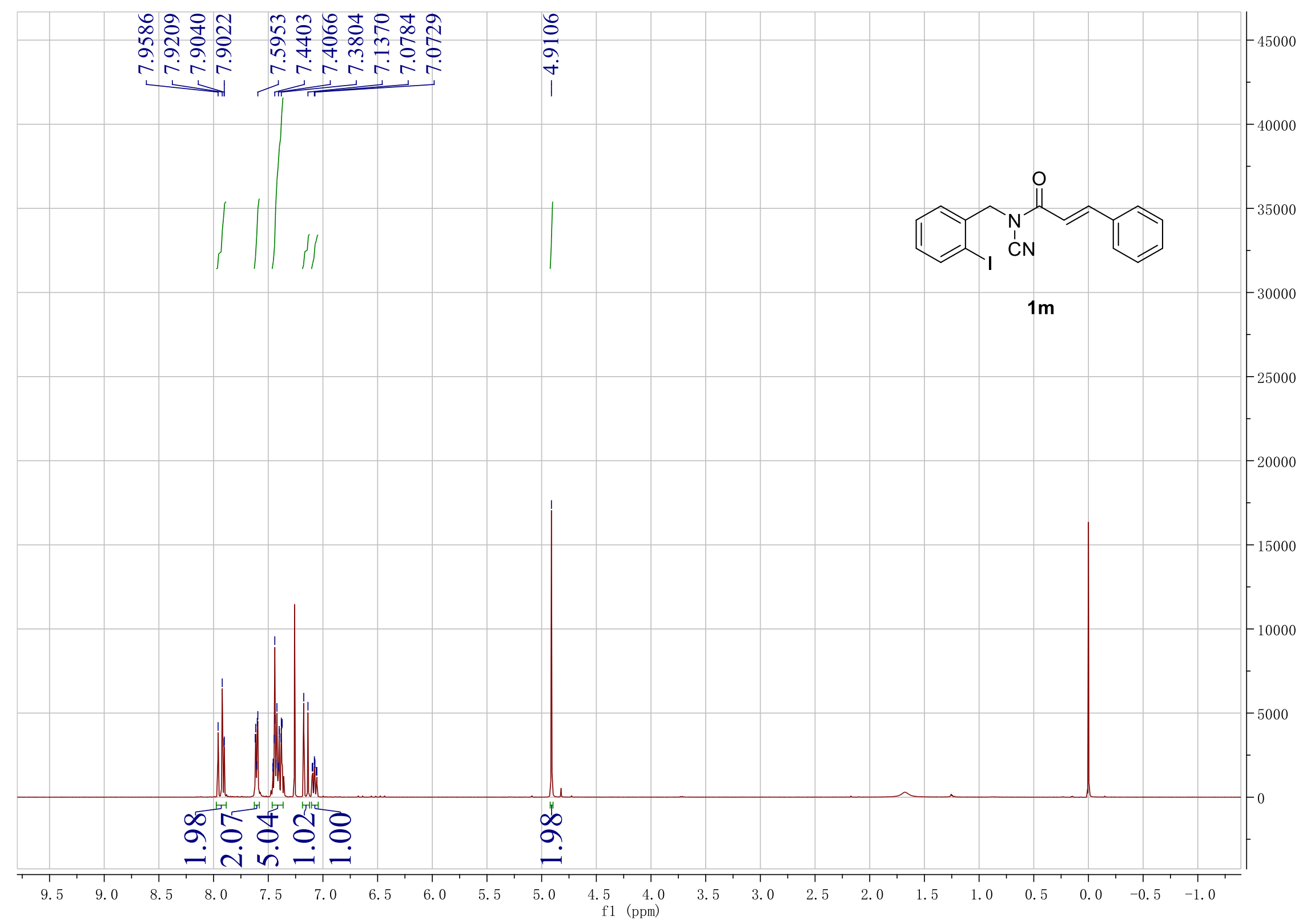




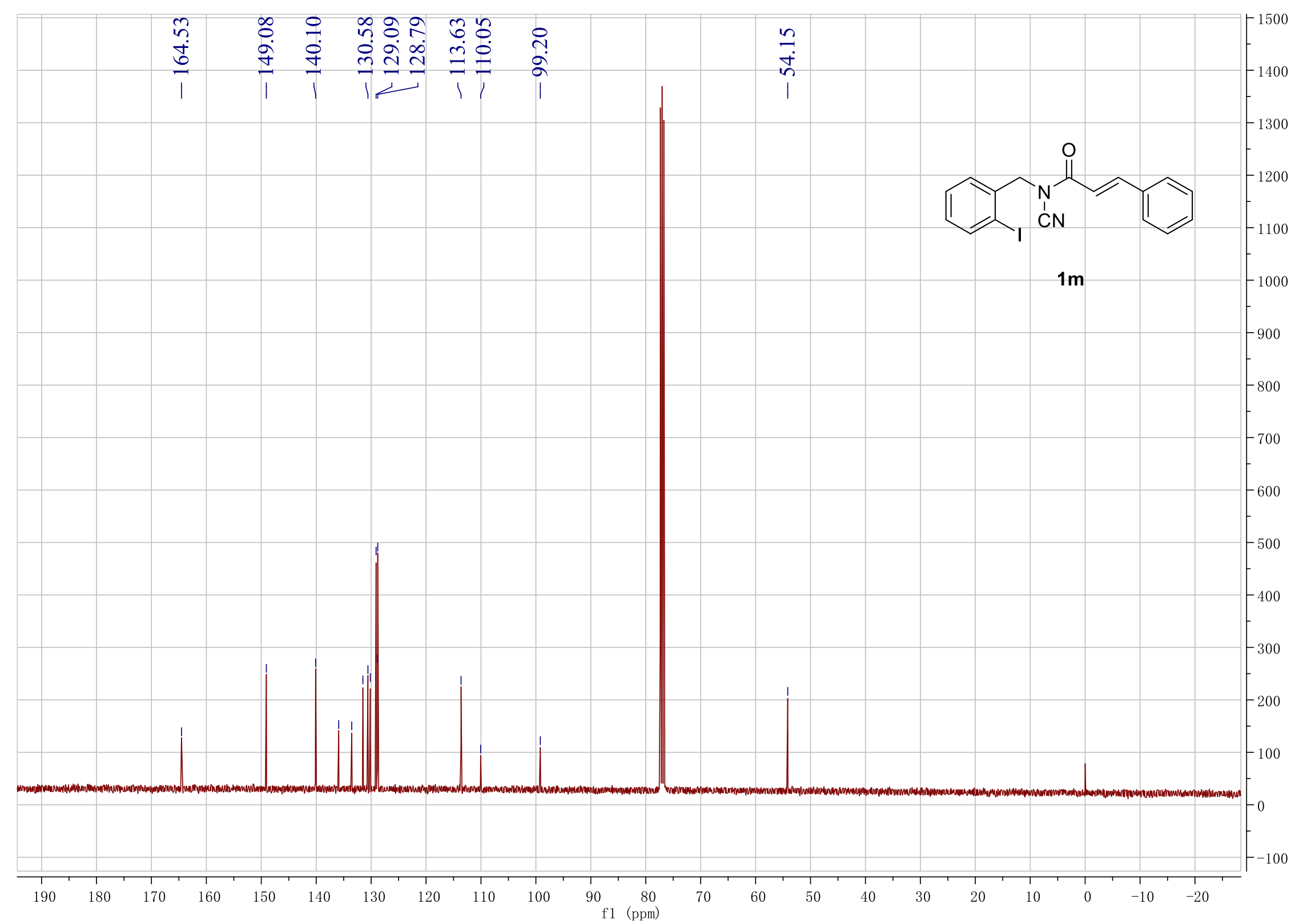




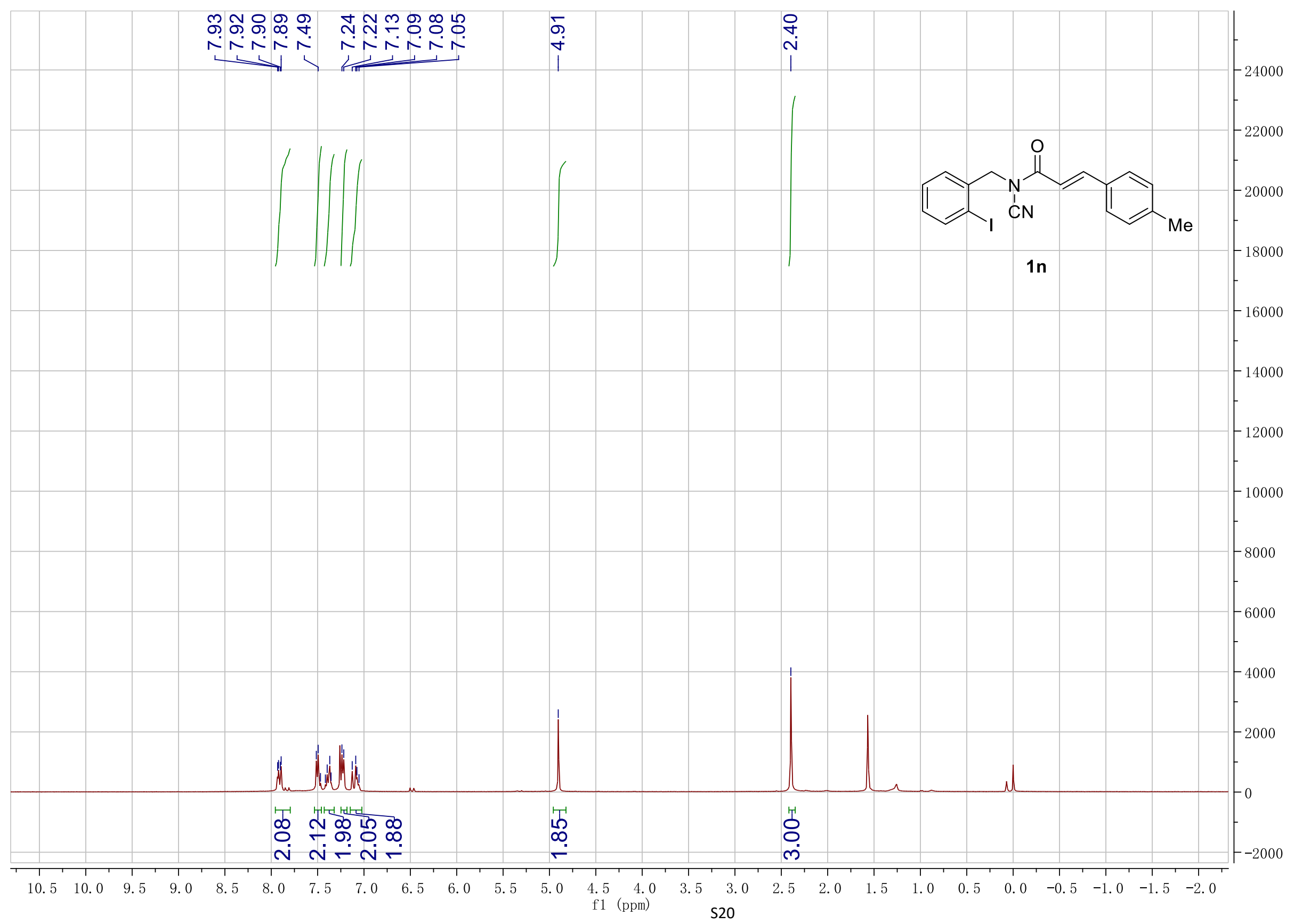



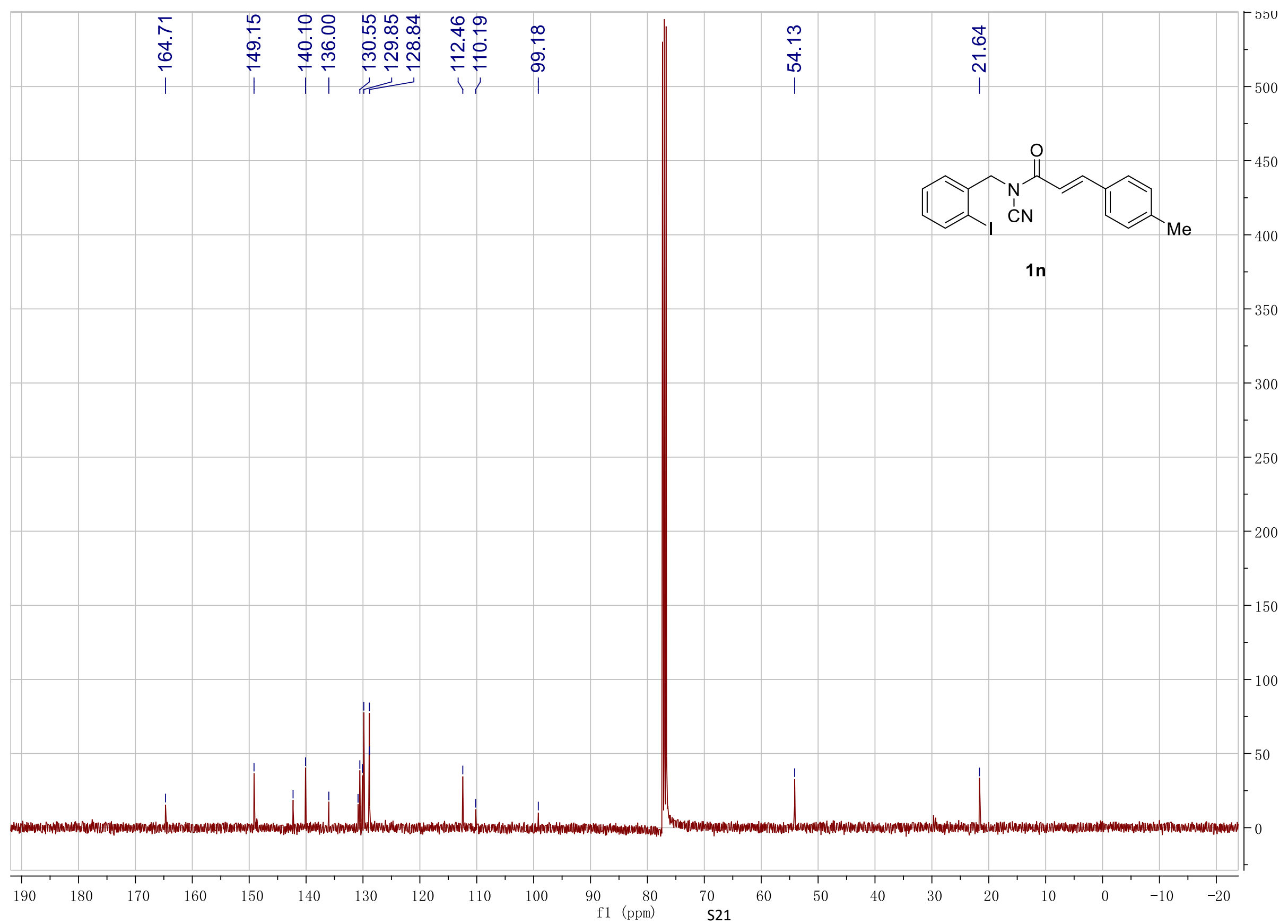


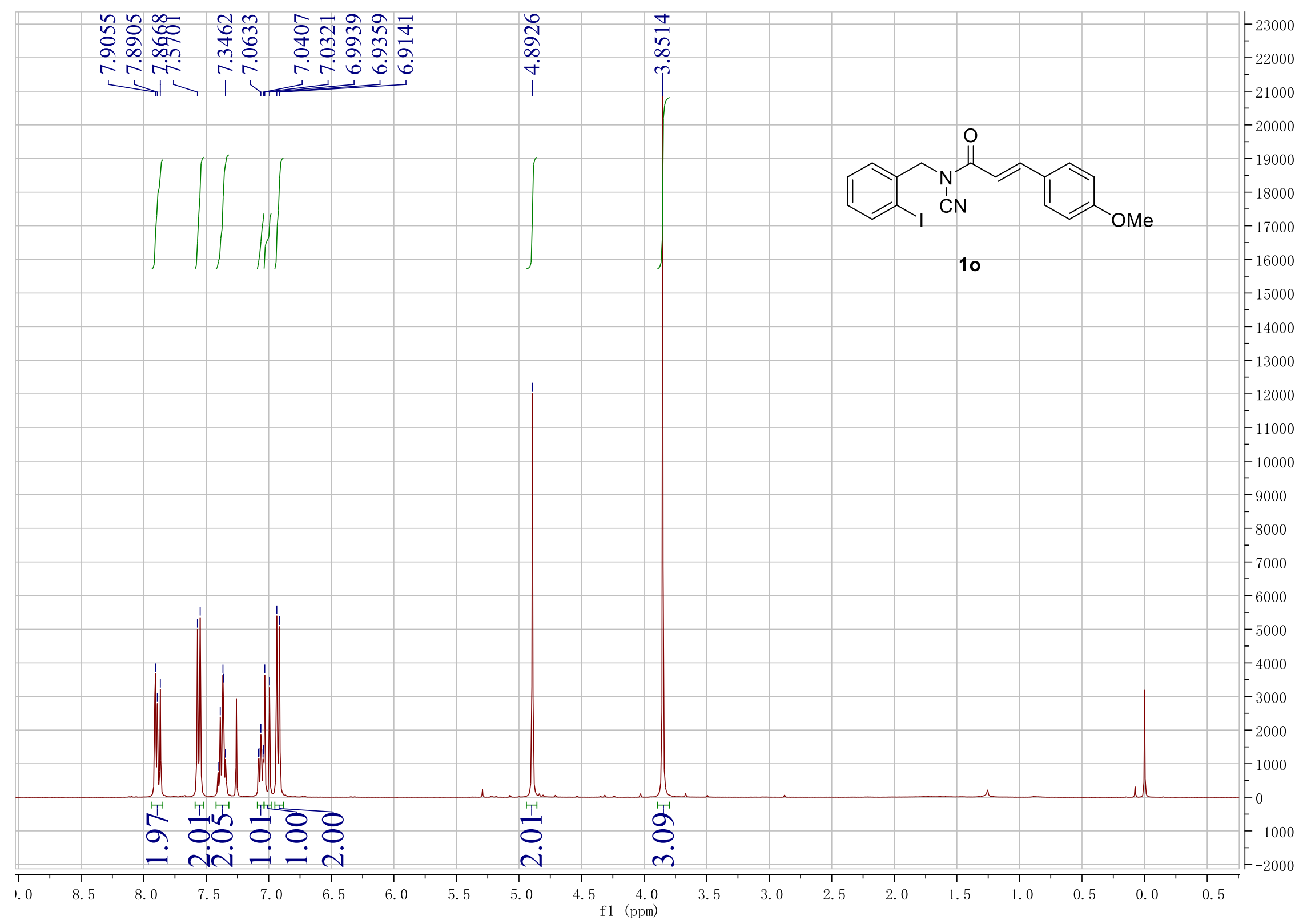














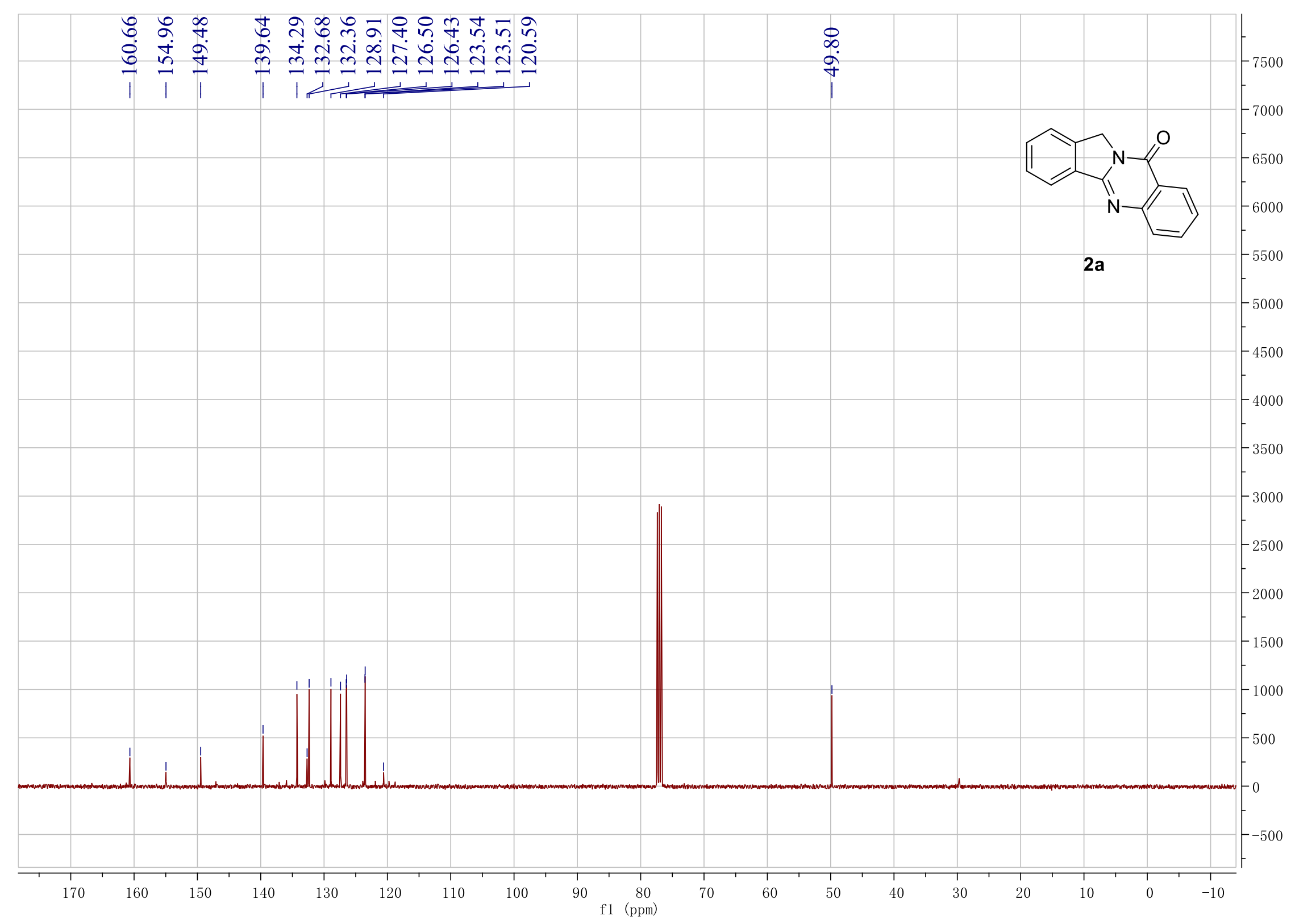




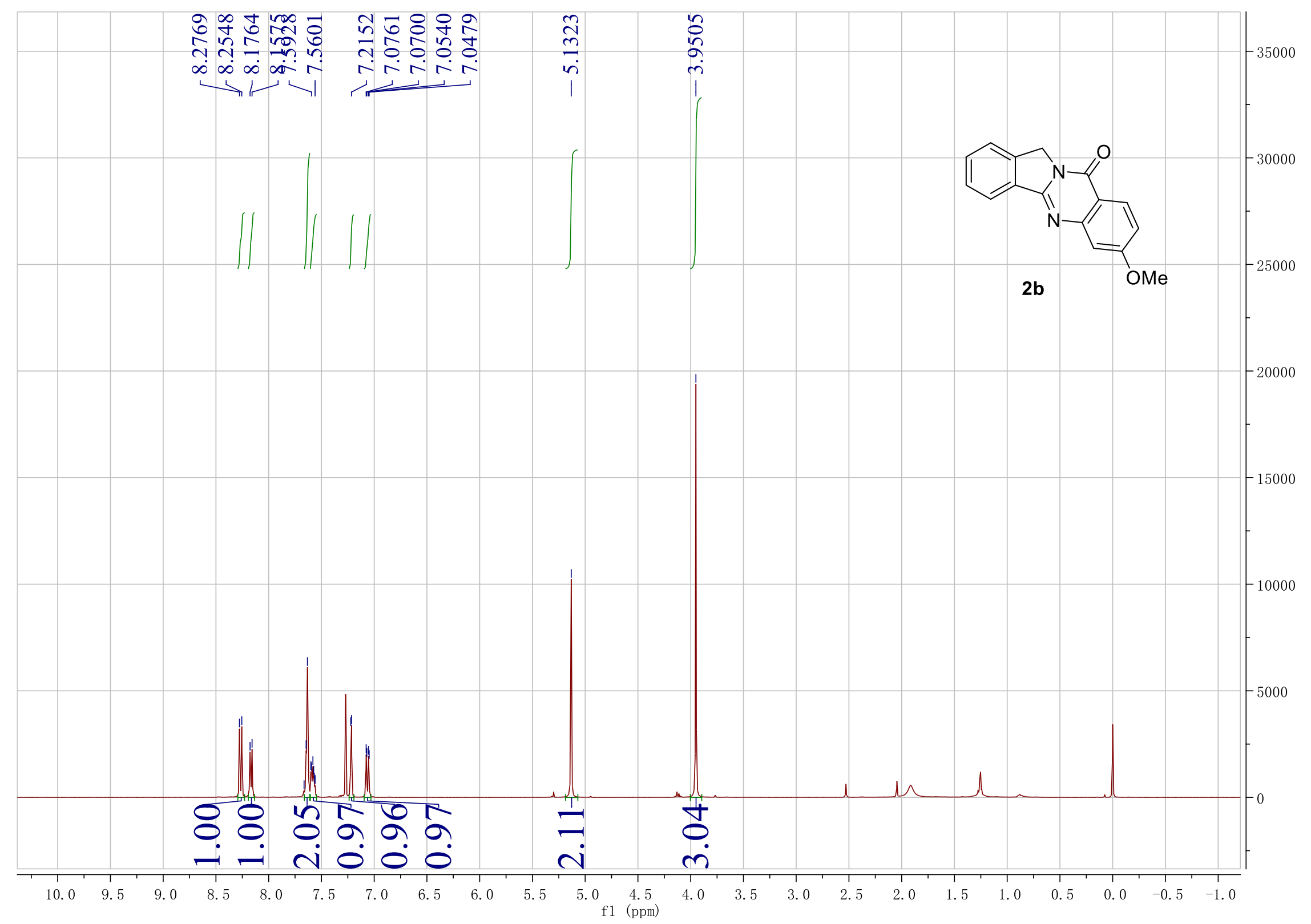




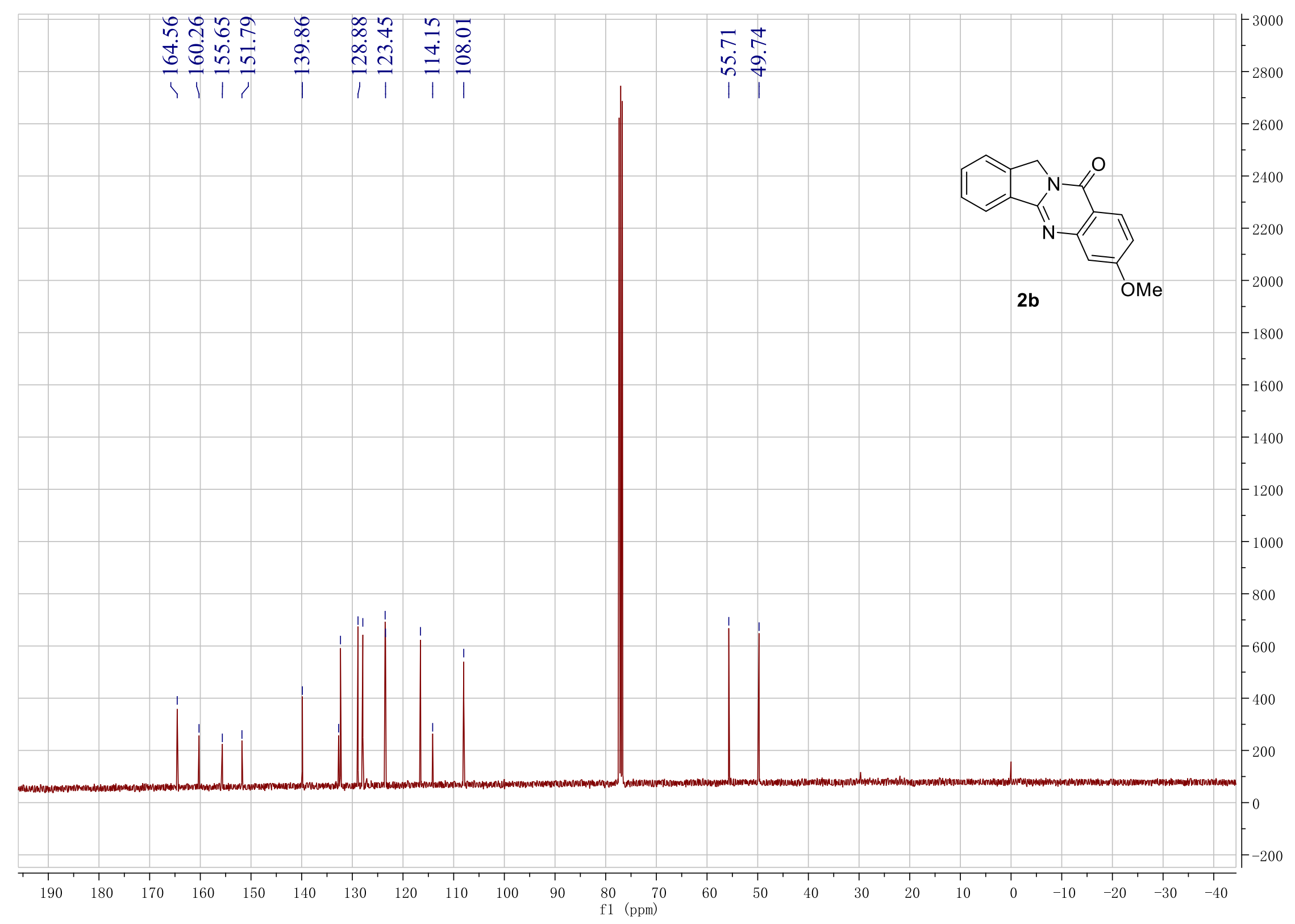




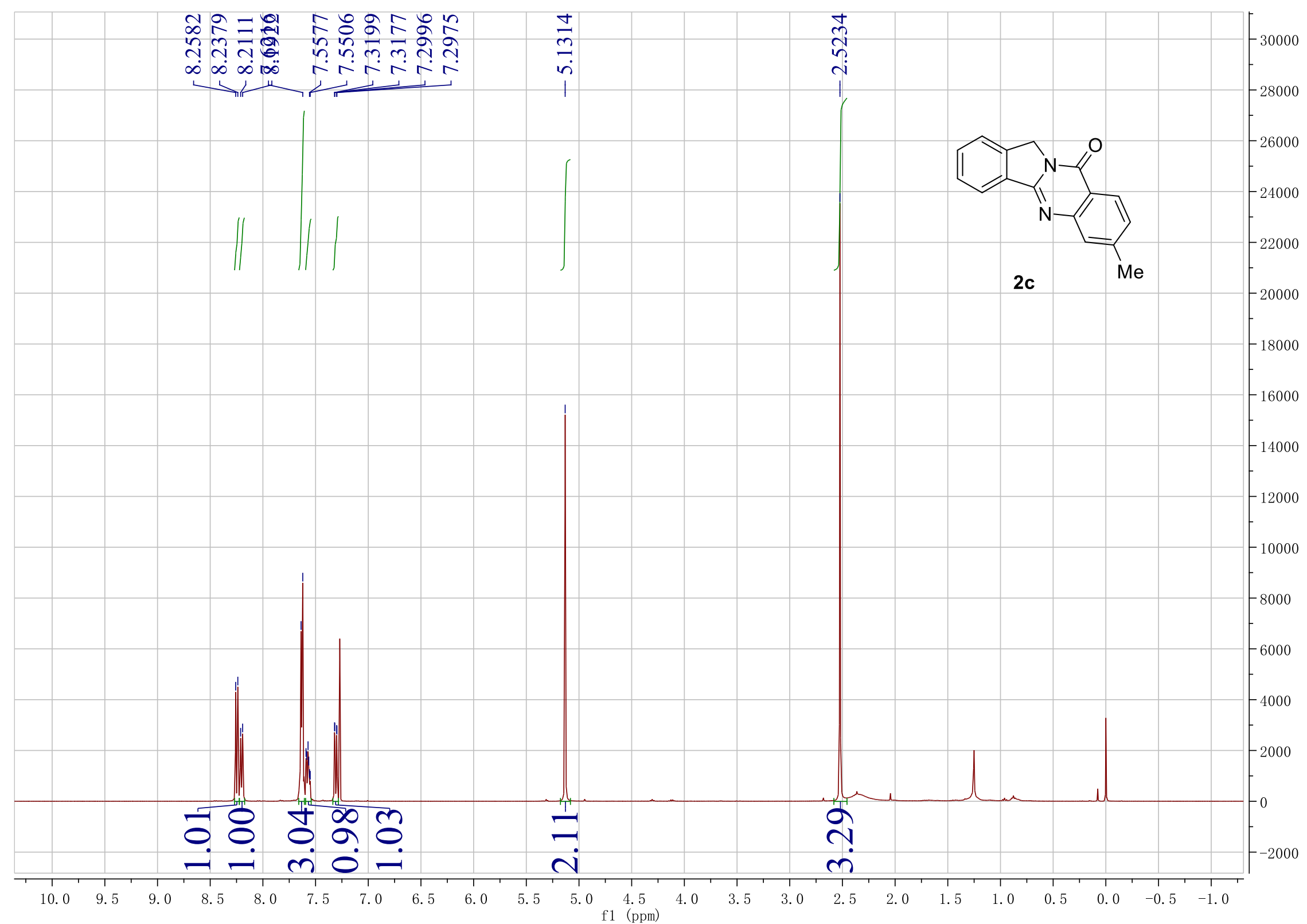




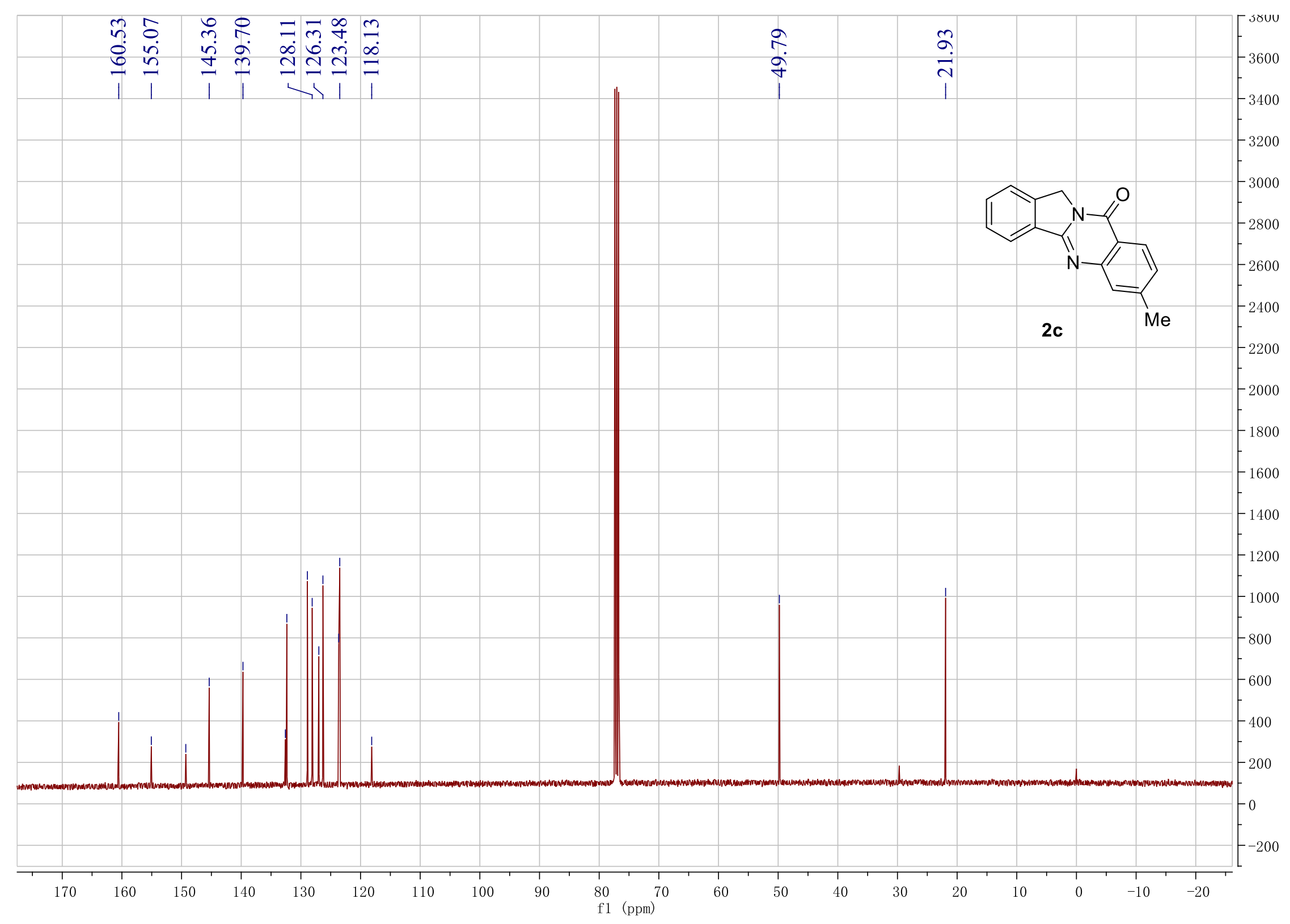




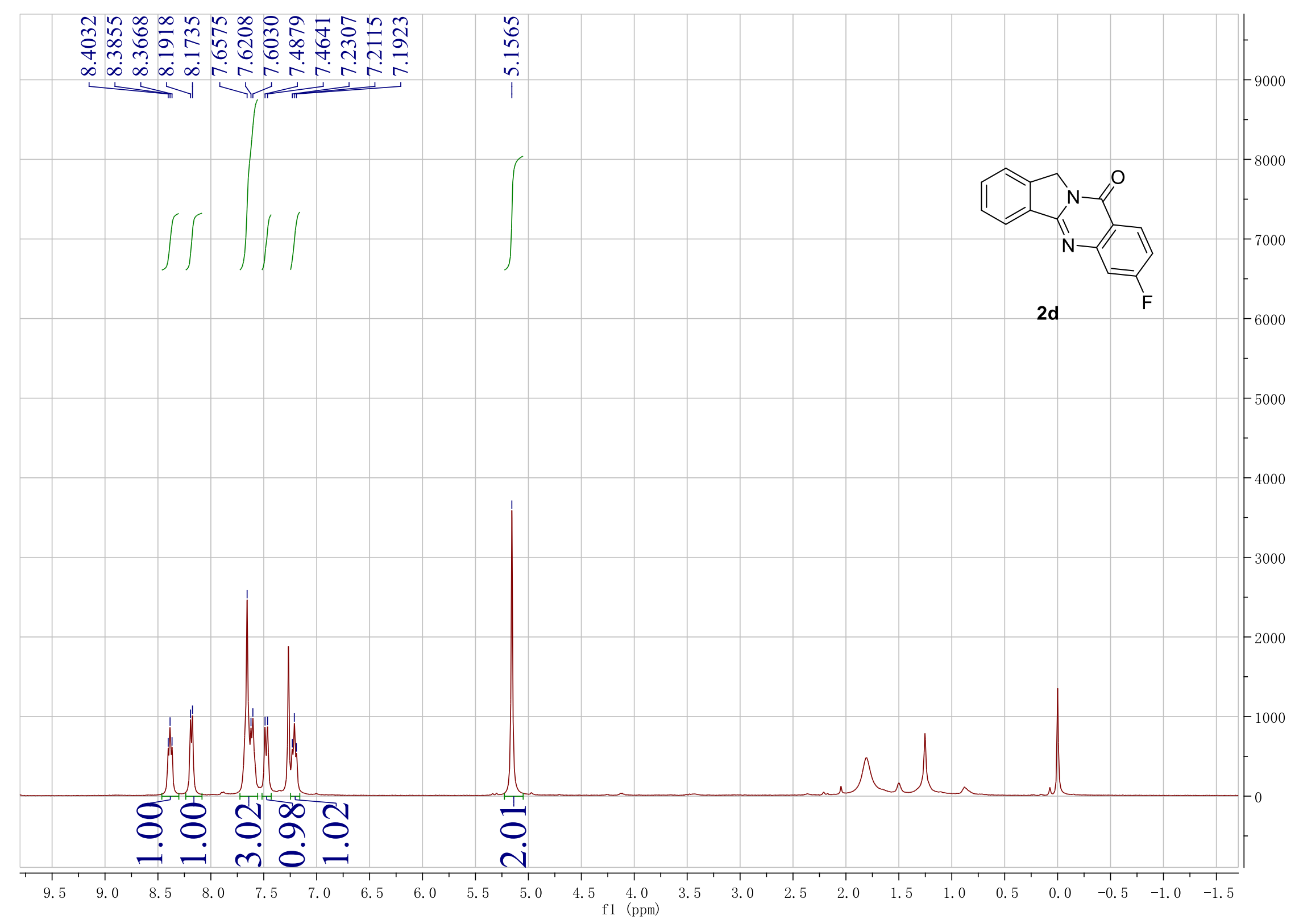




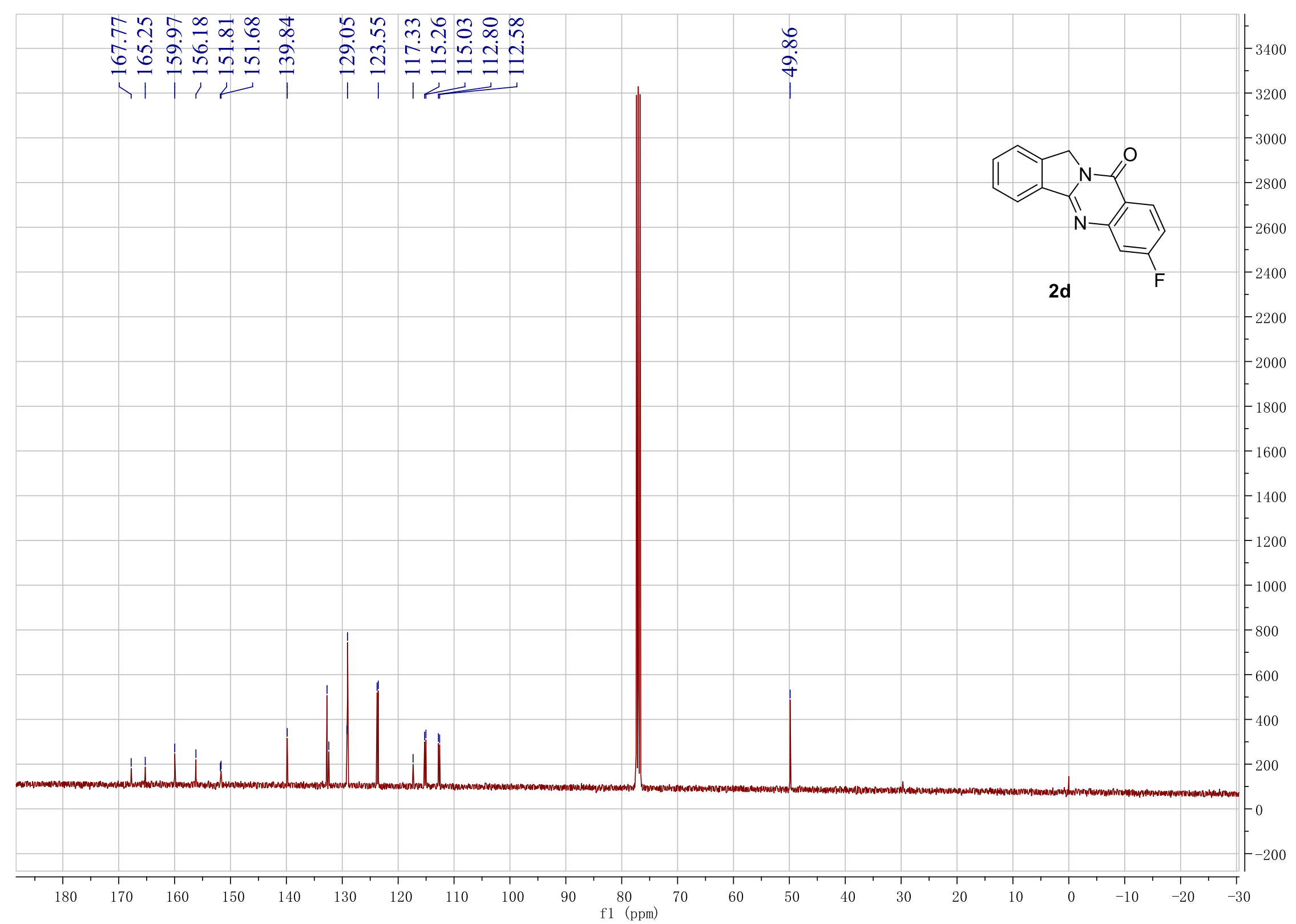









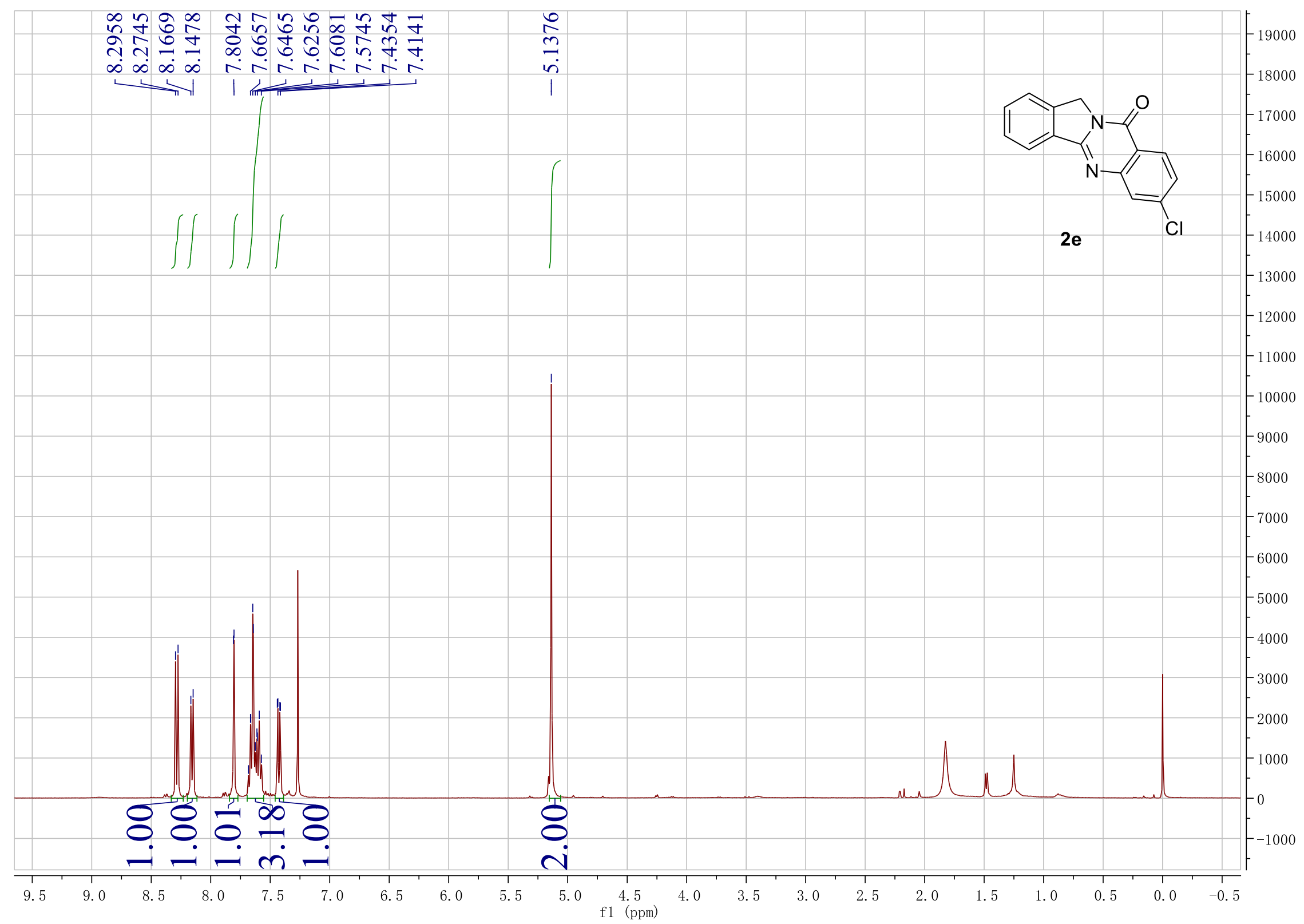




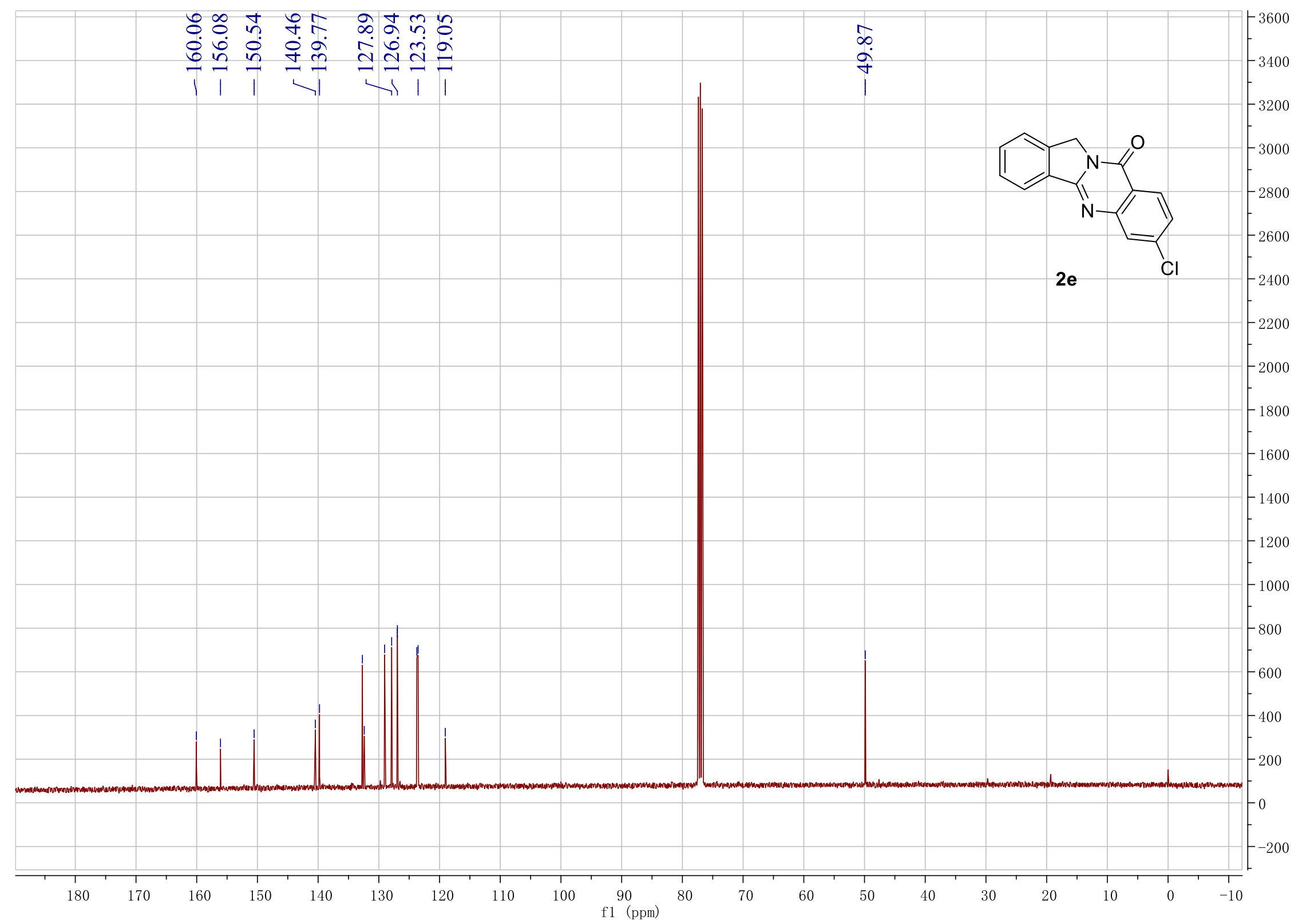




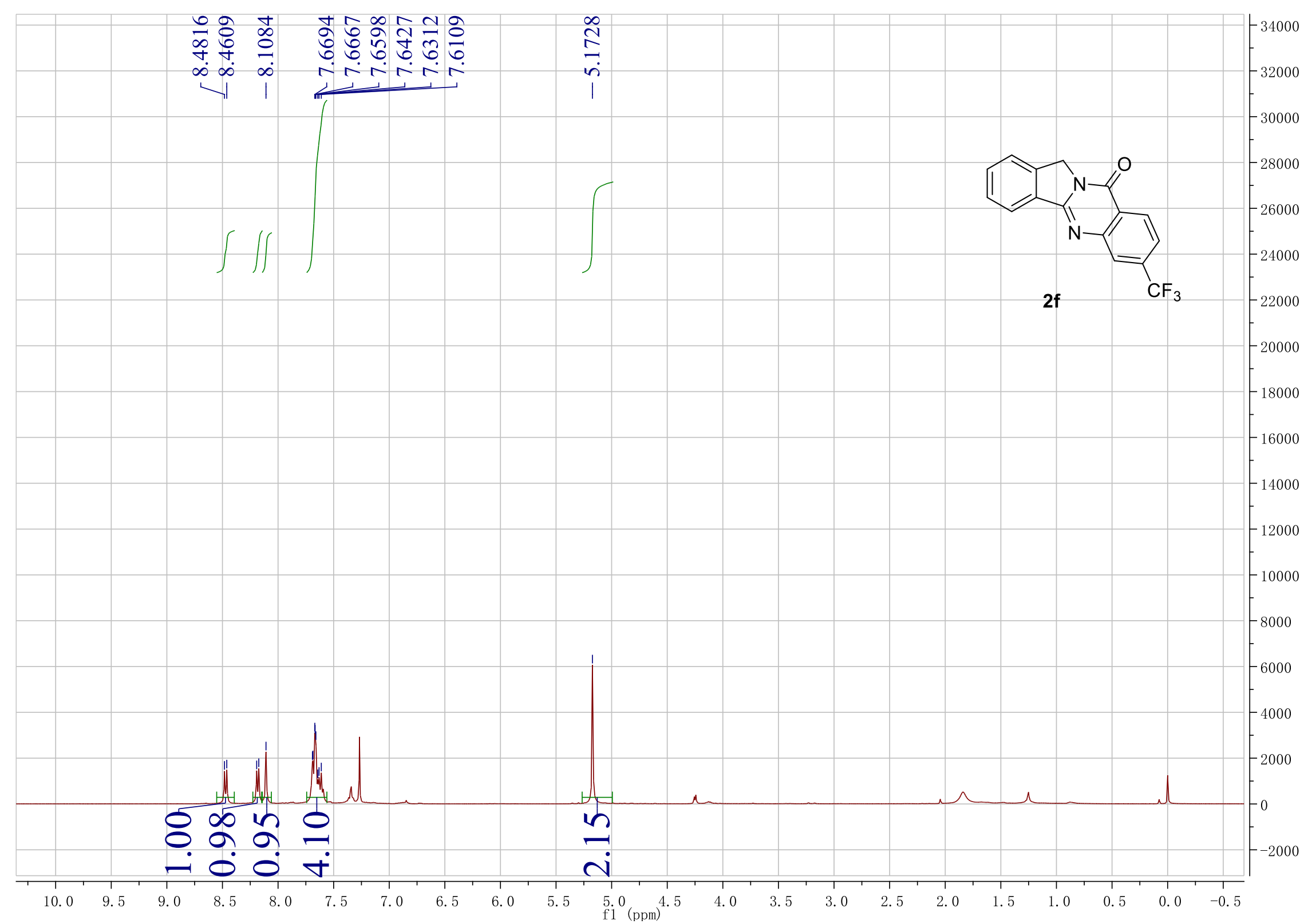




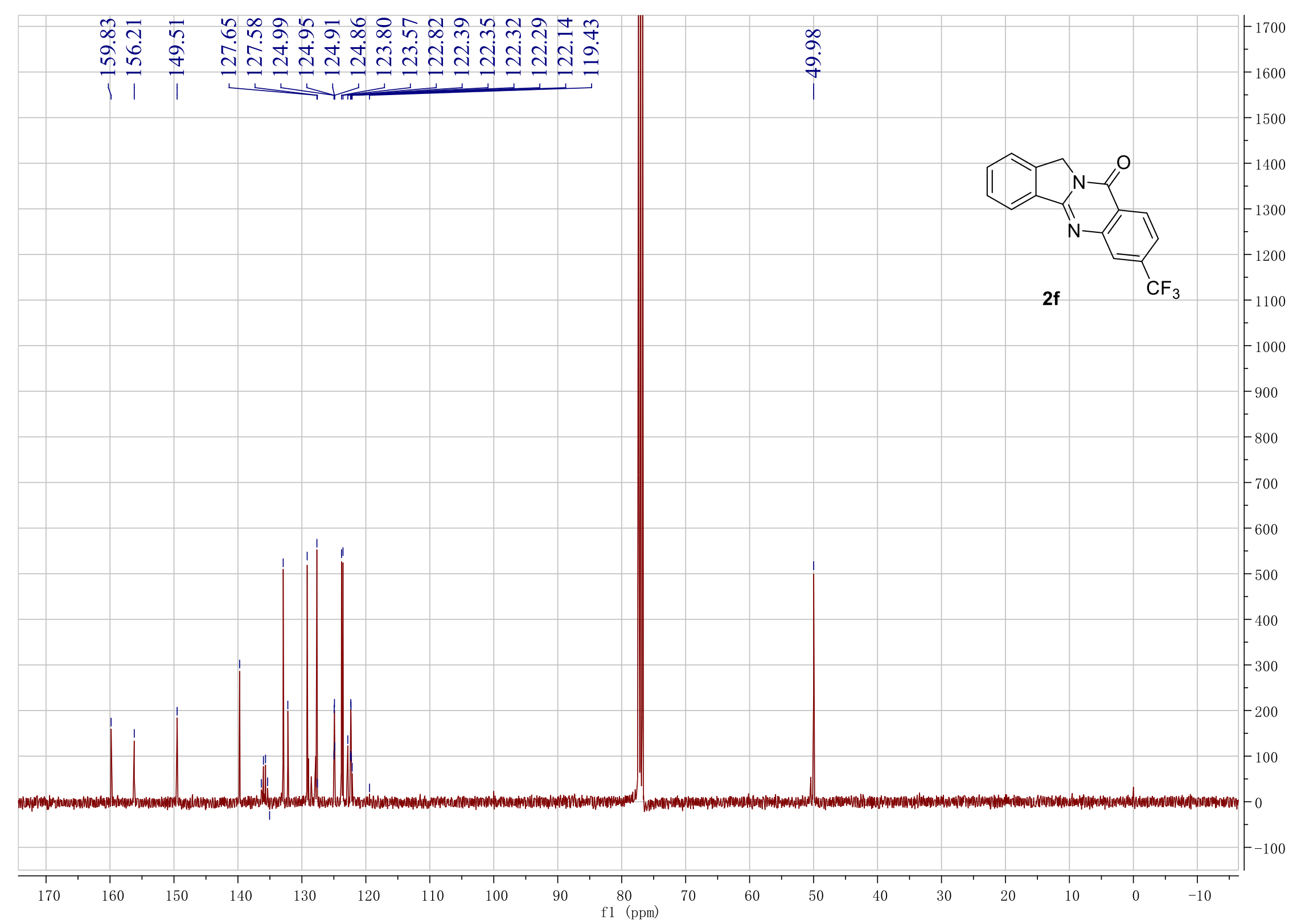




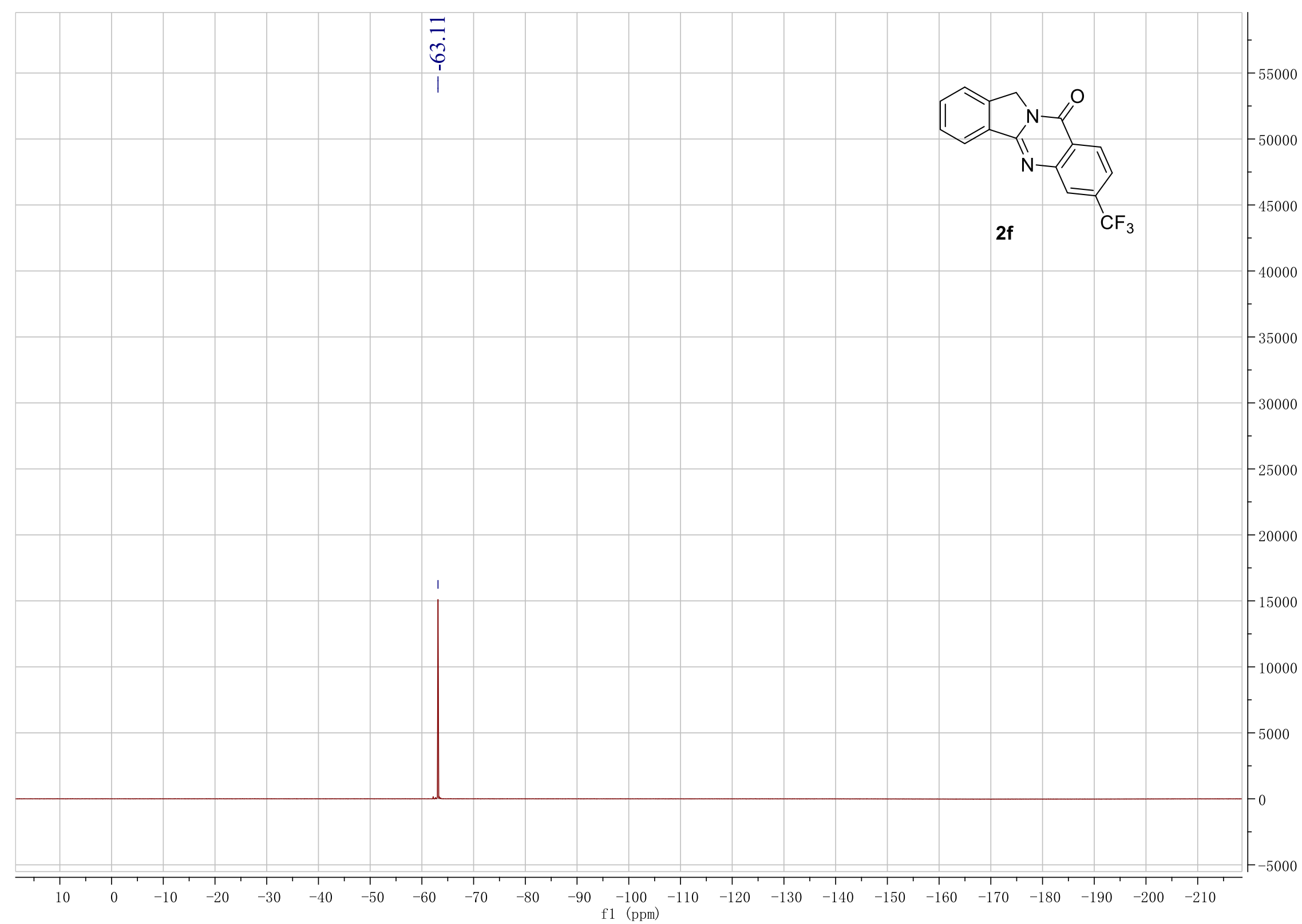




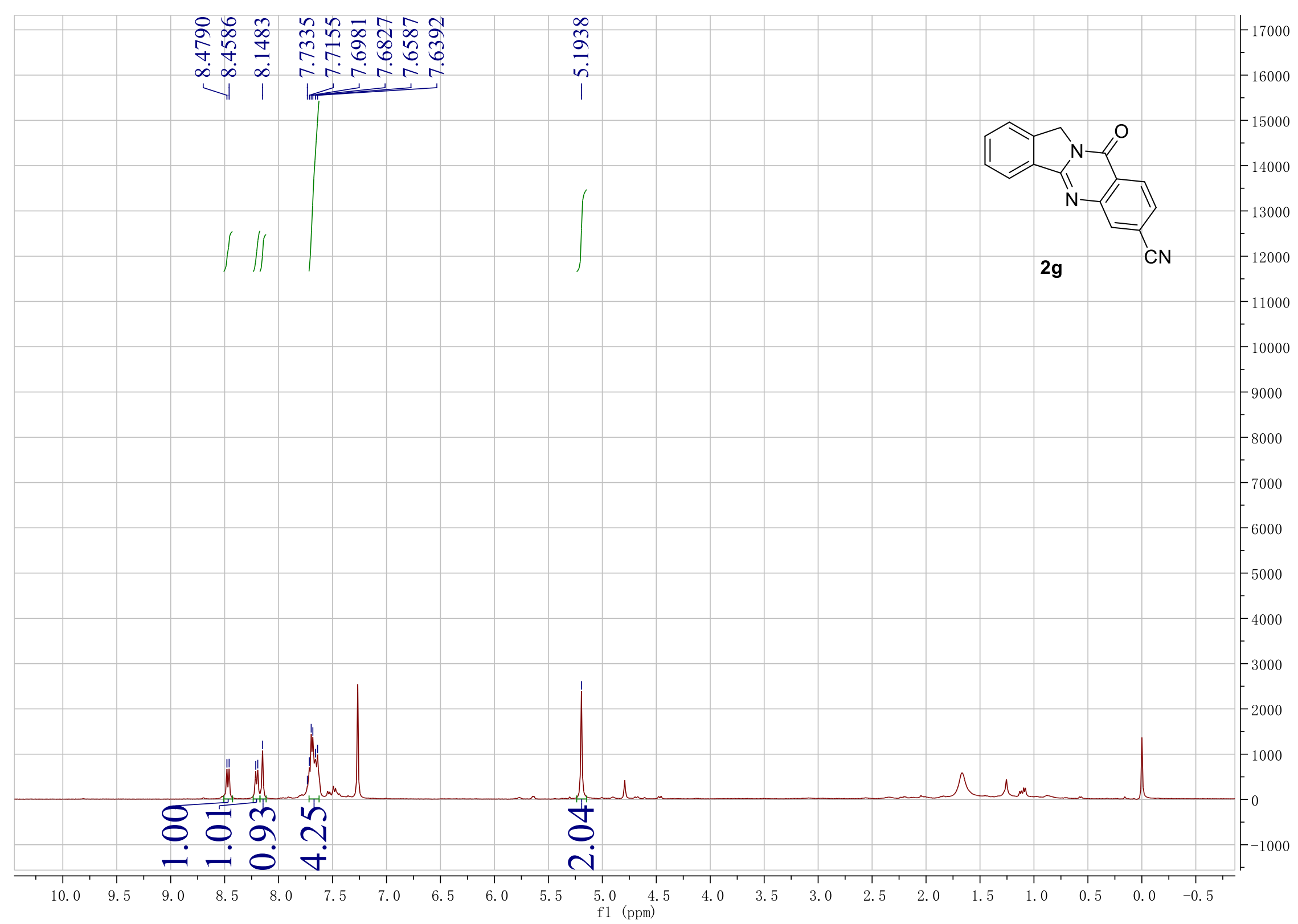




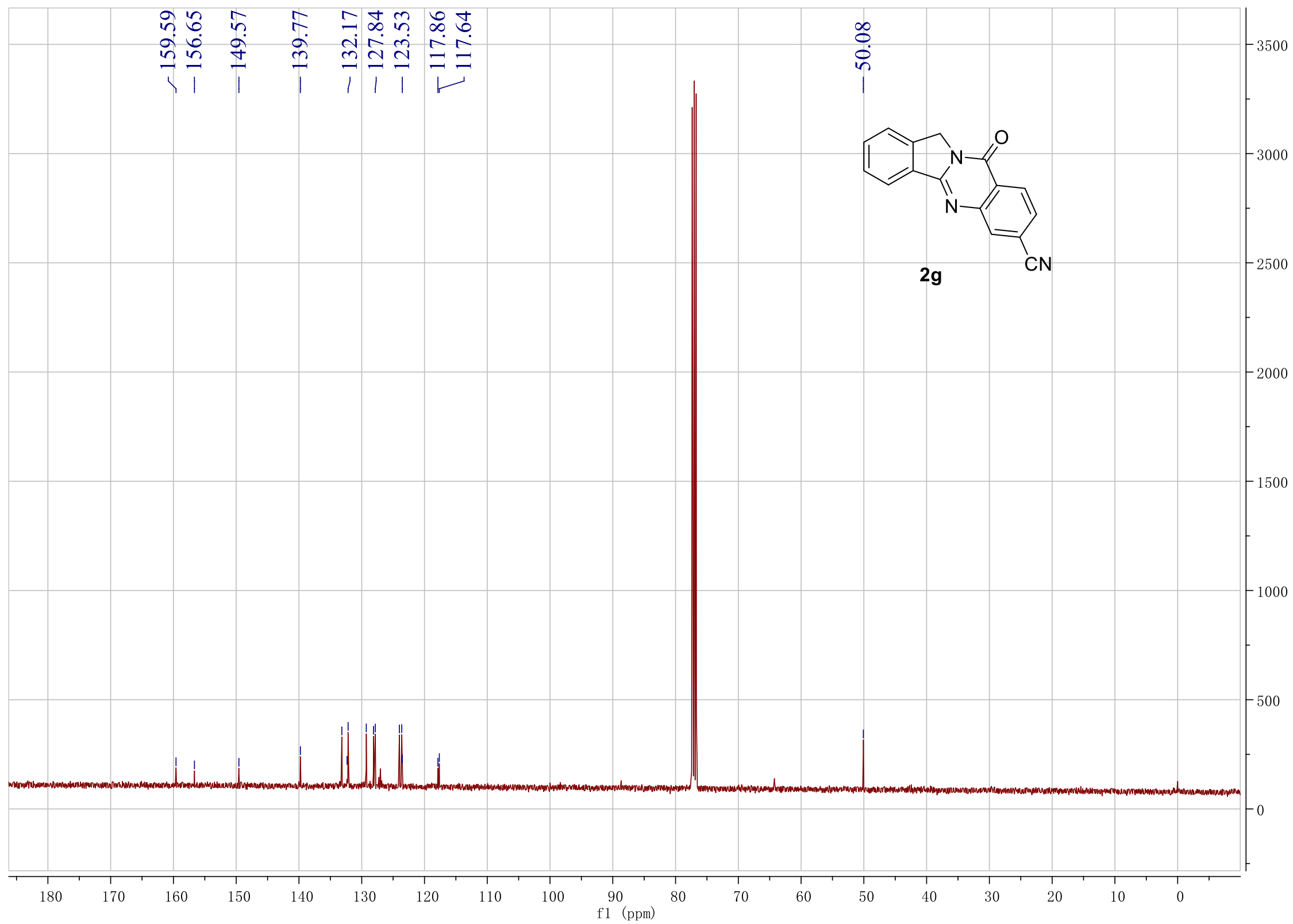

S39 


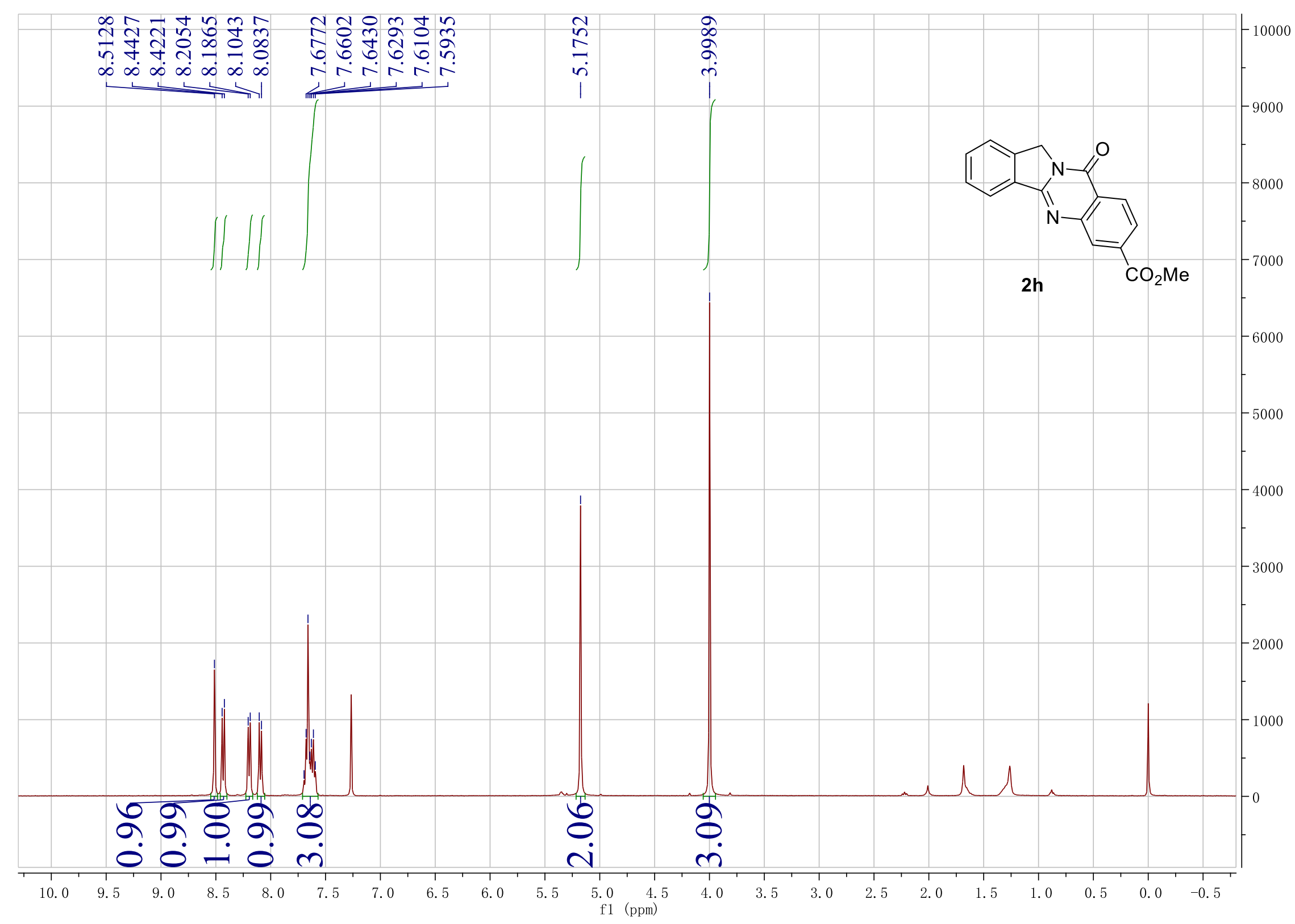




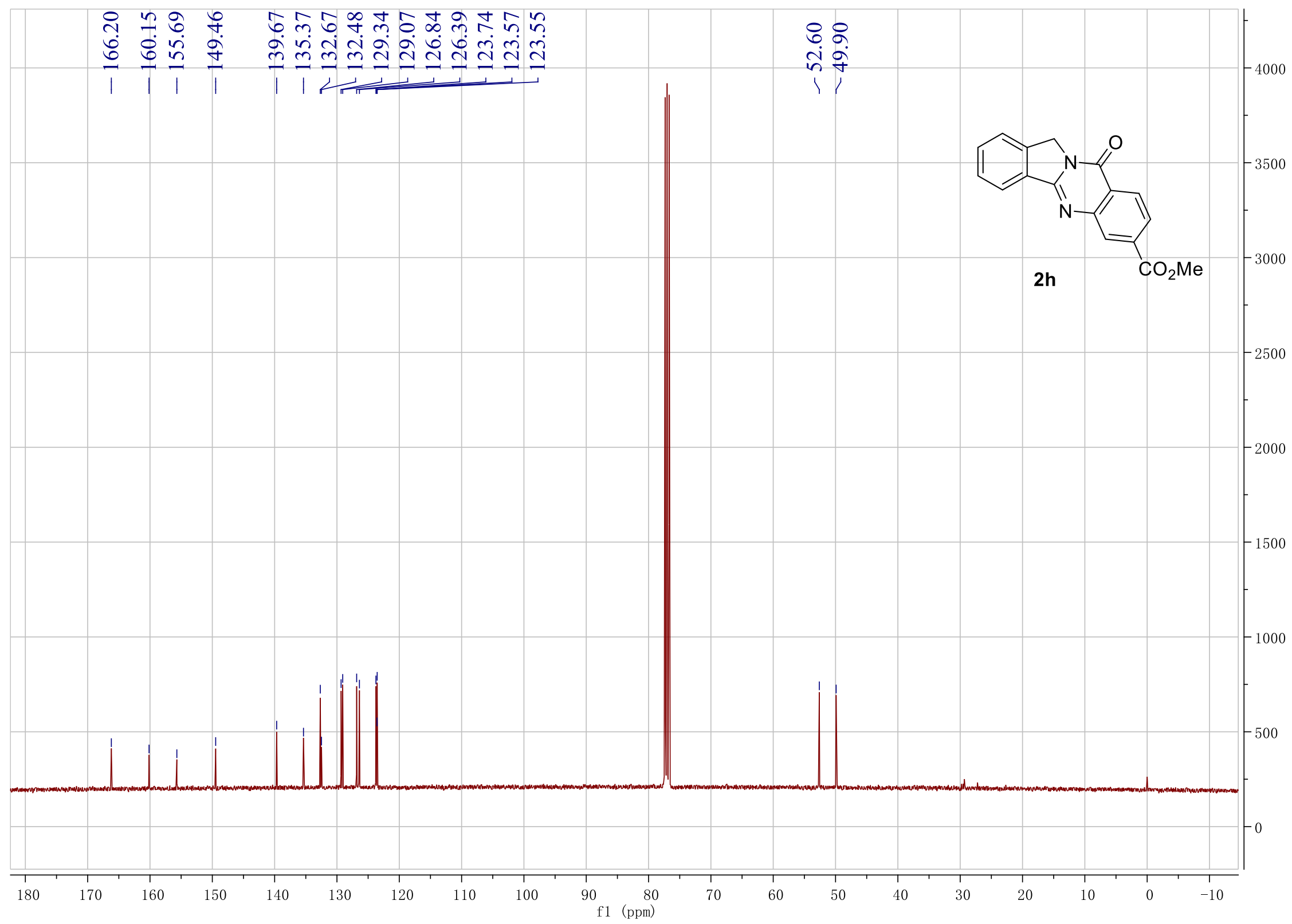

S41 


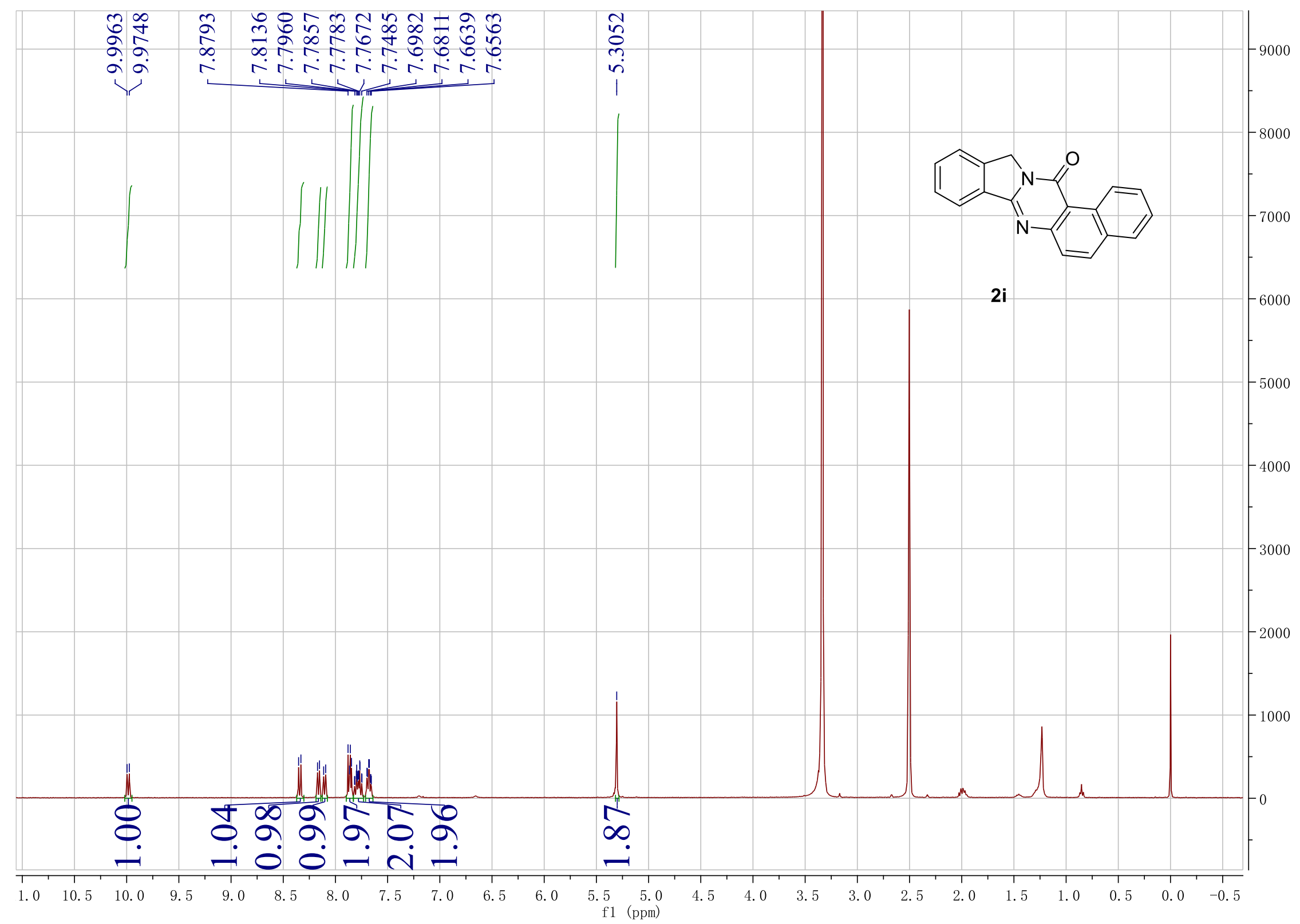




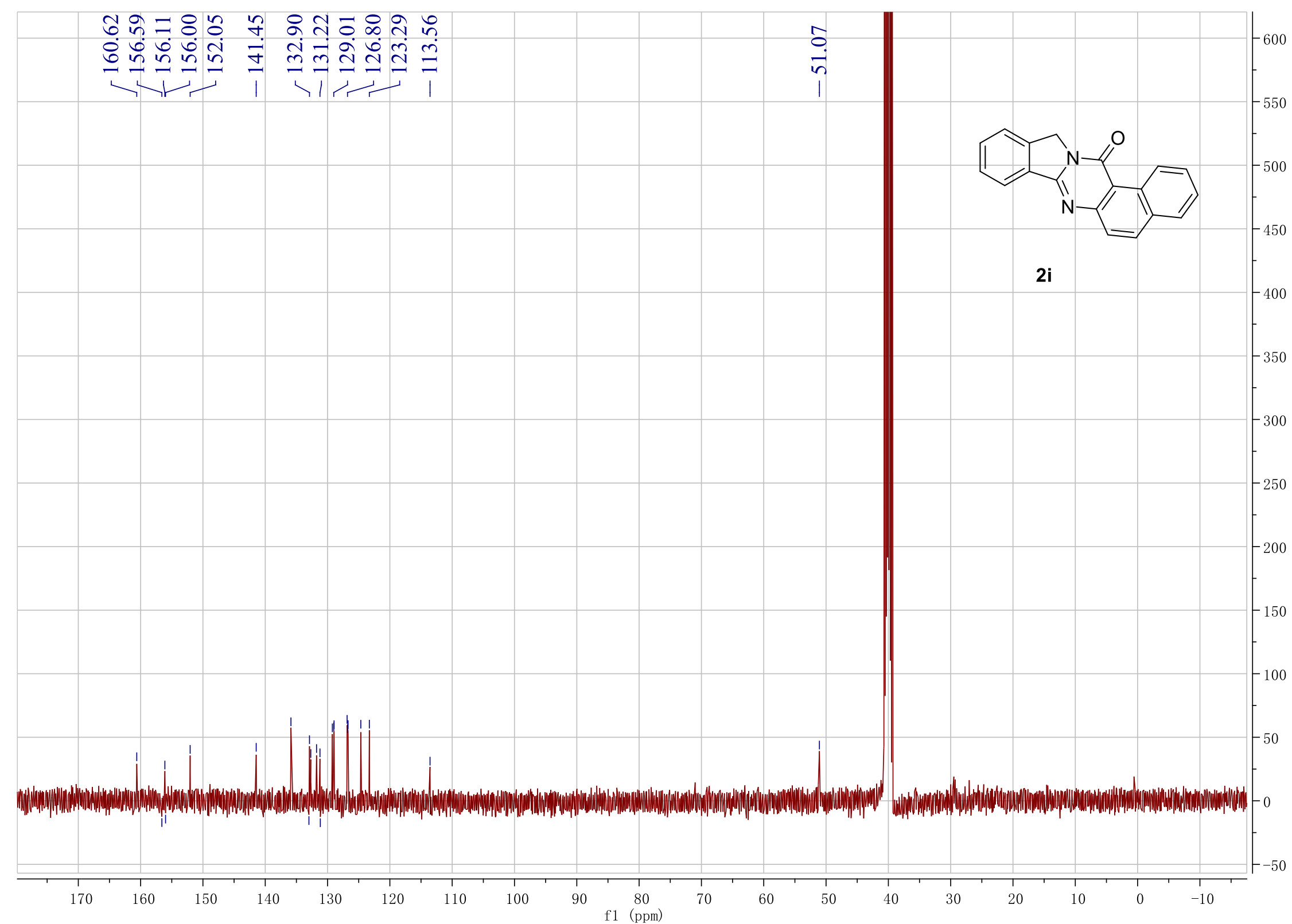




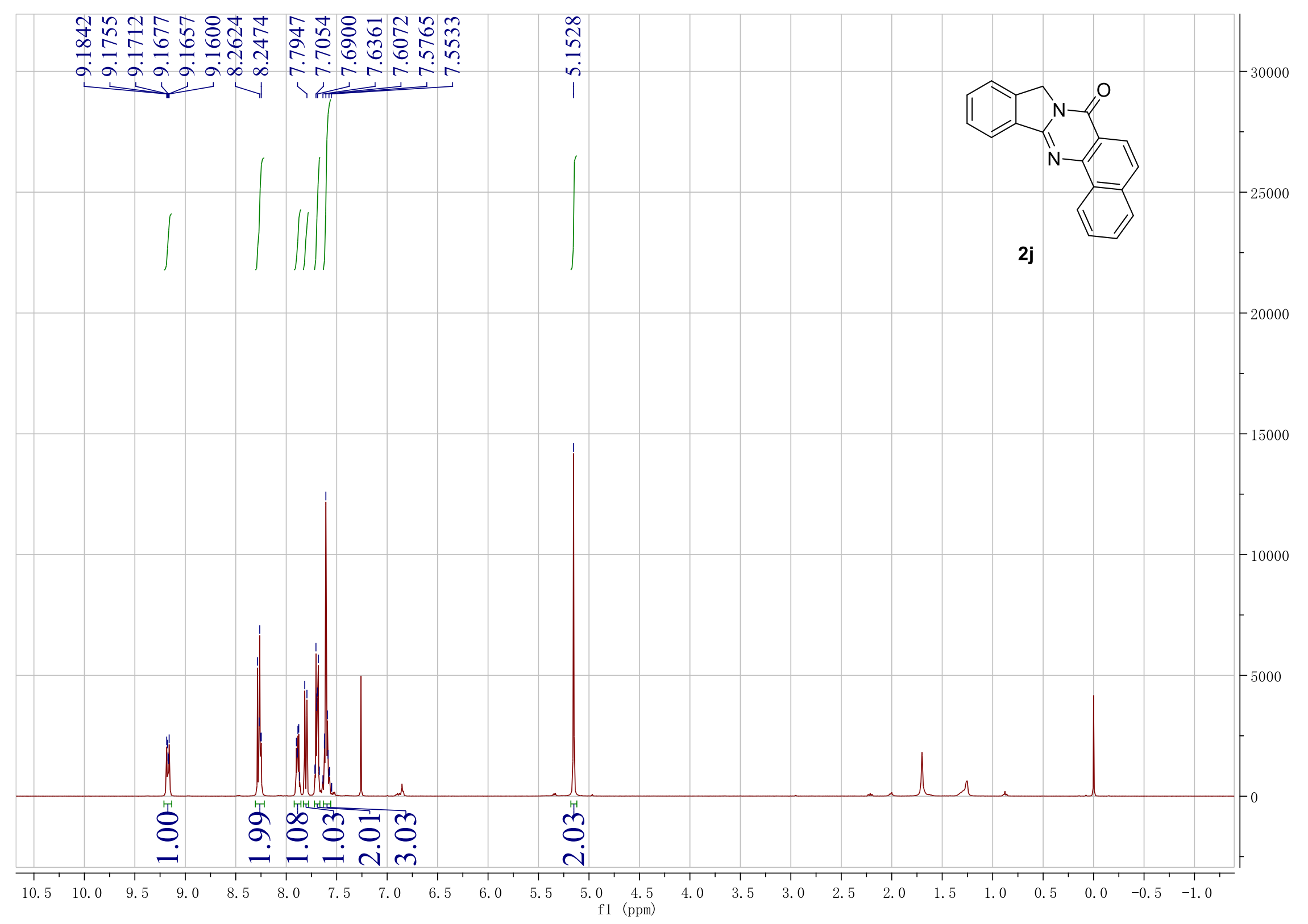




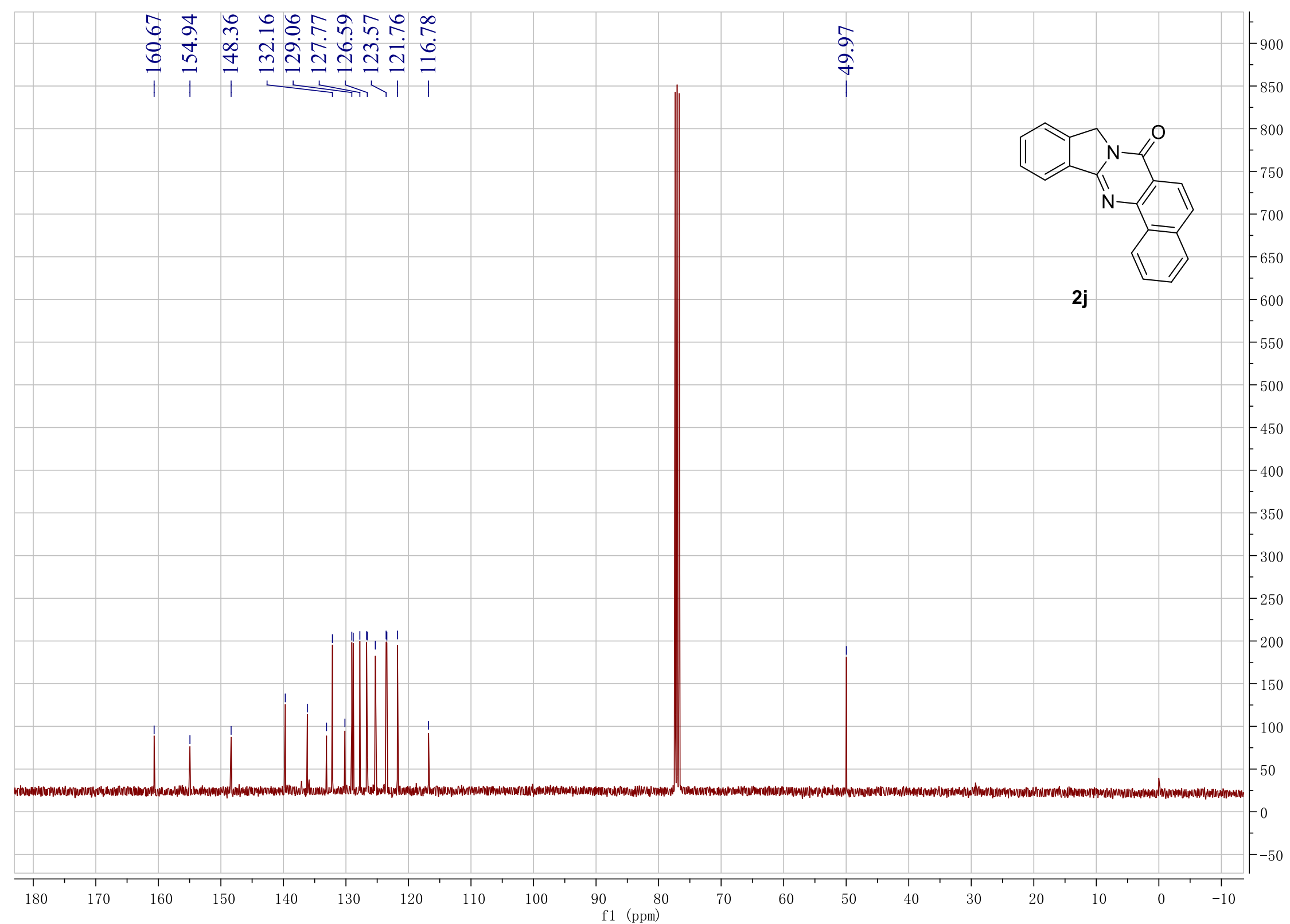




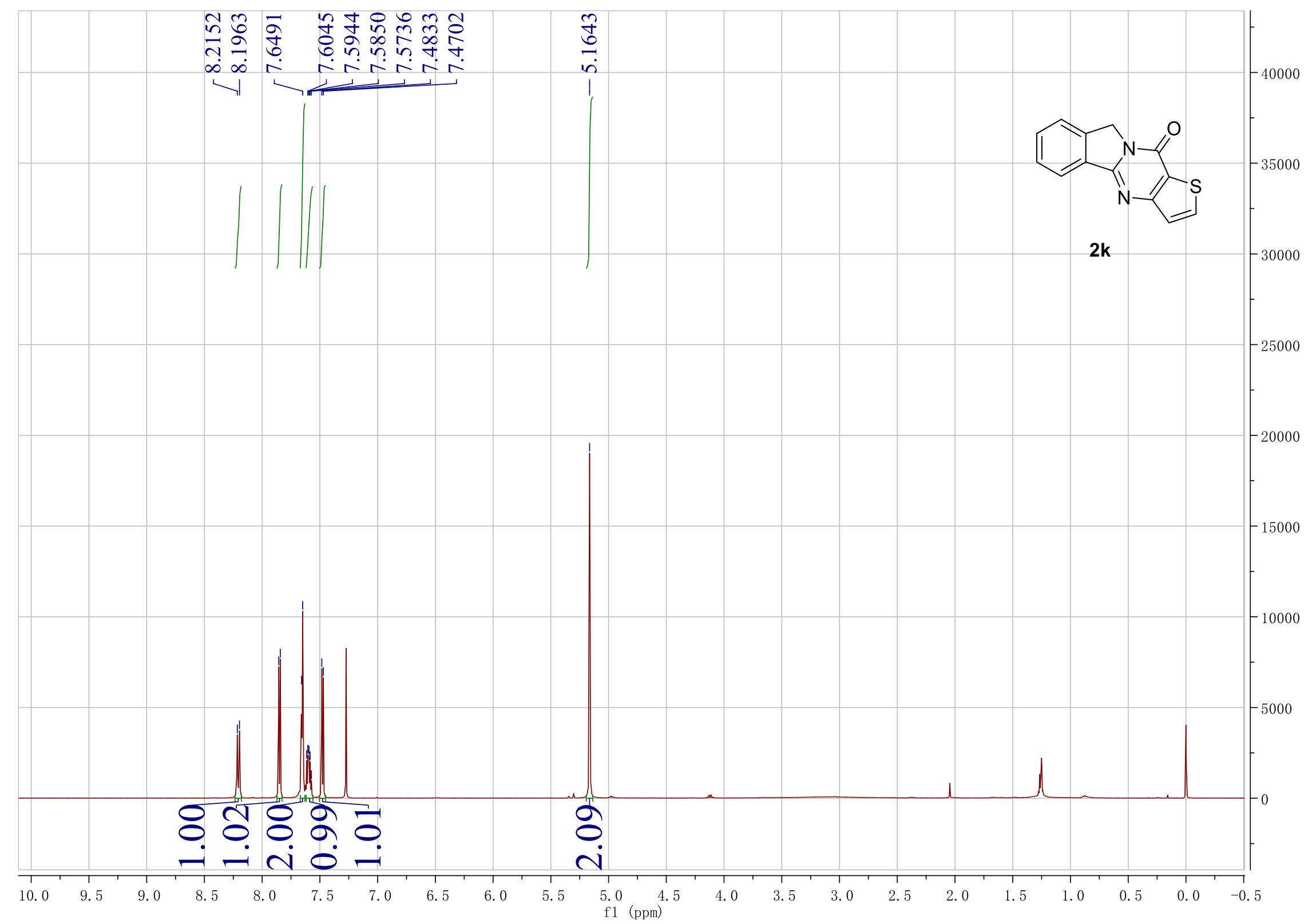




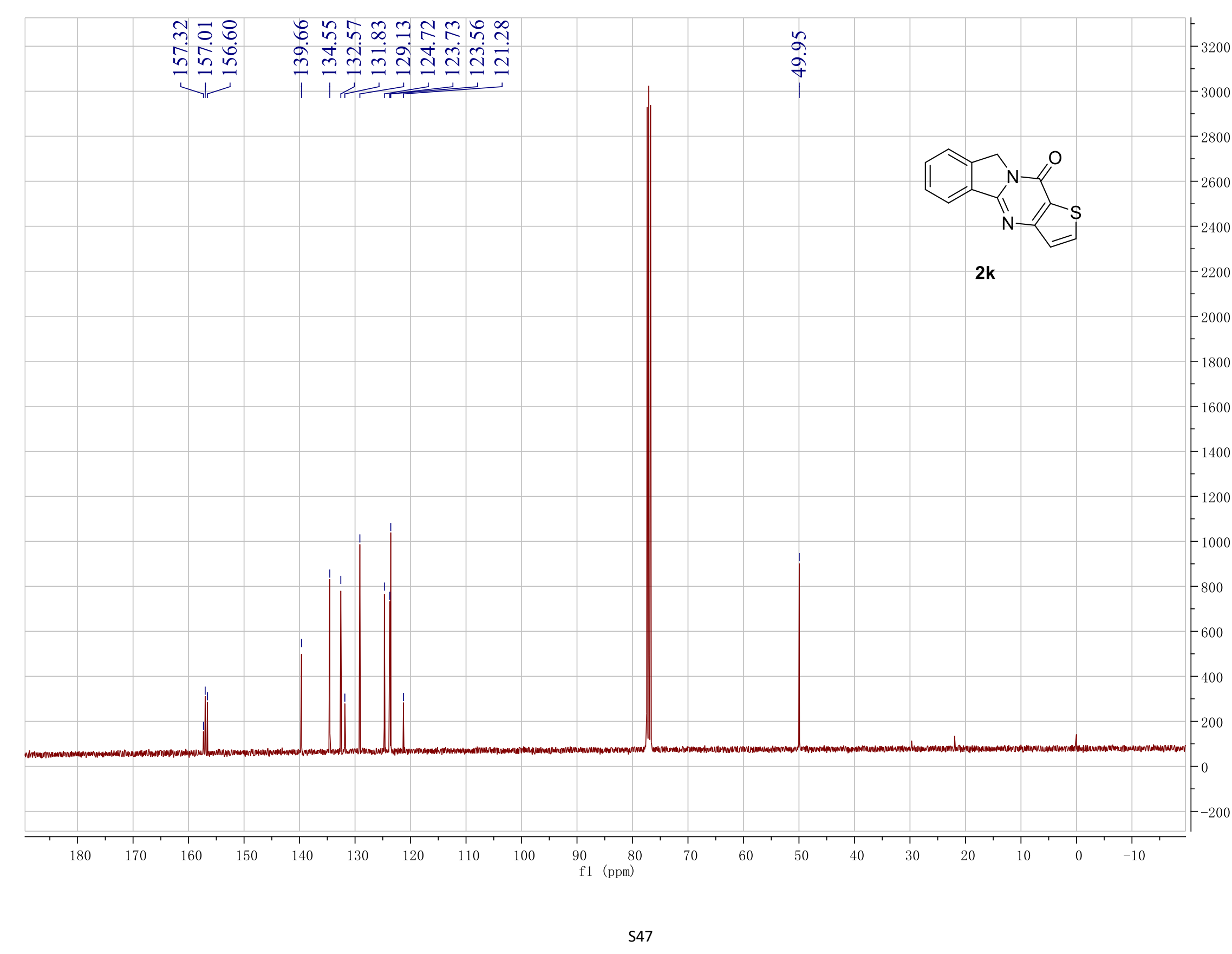




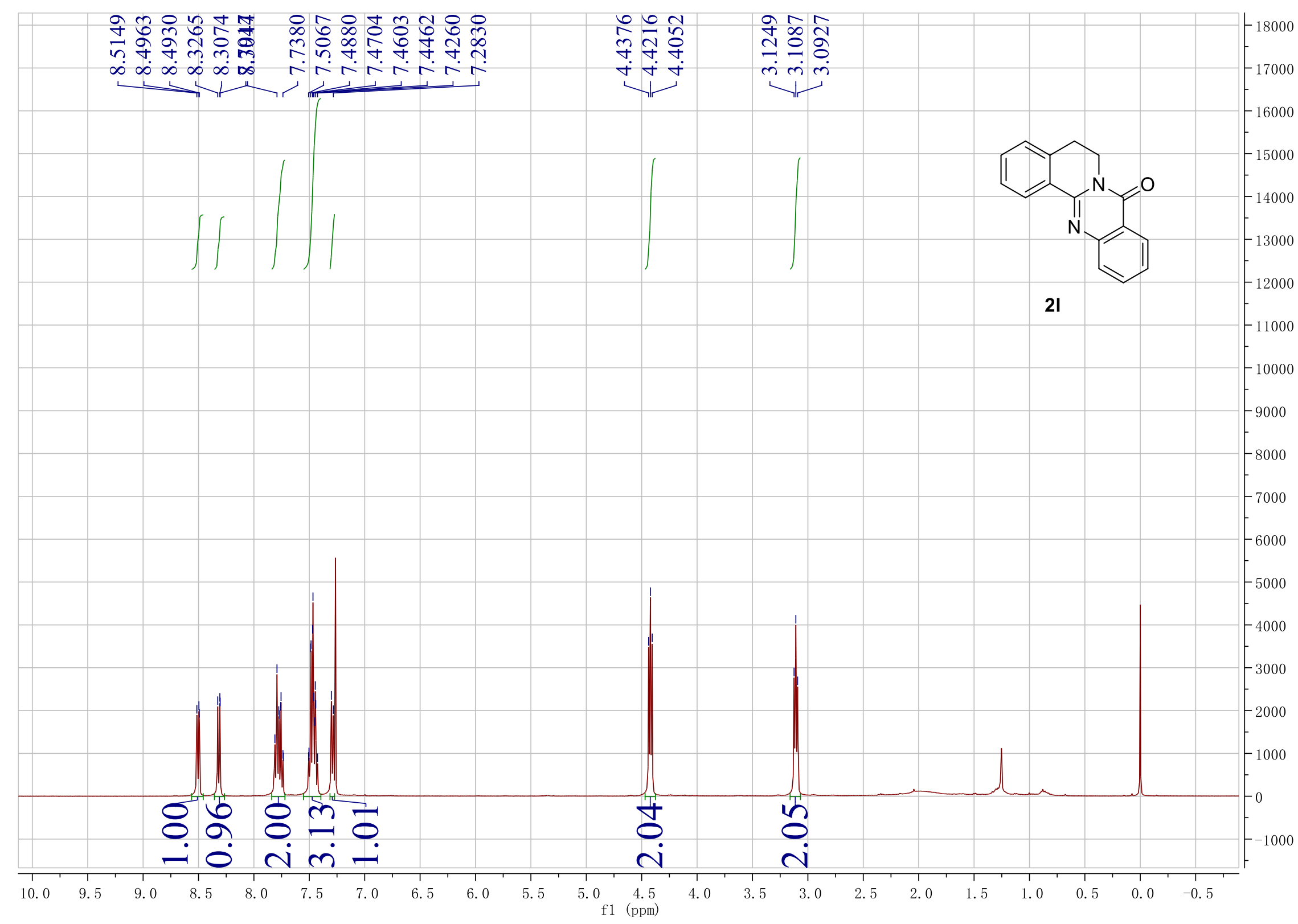




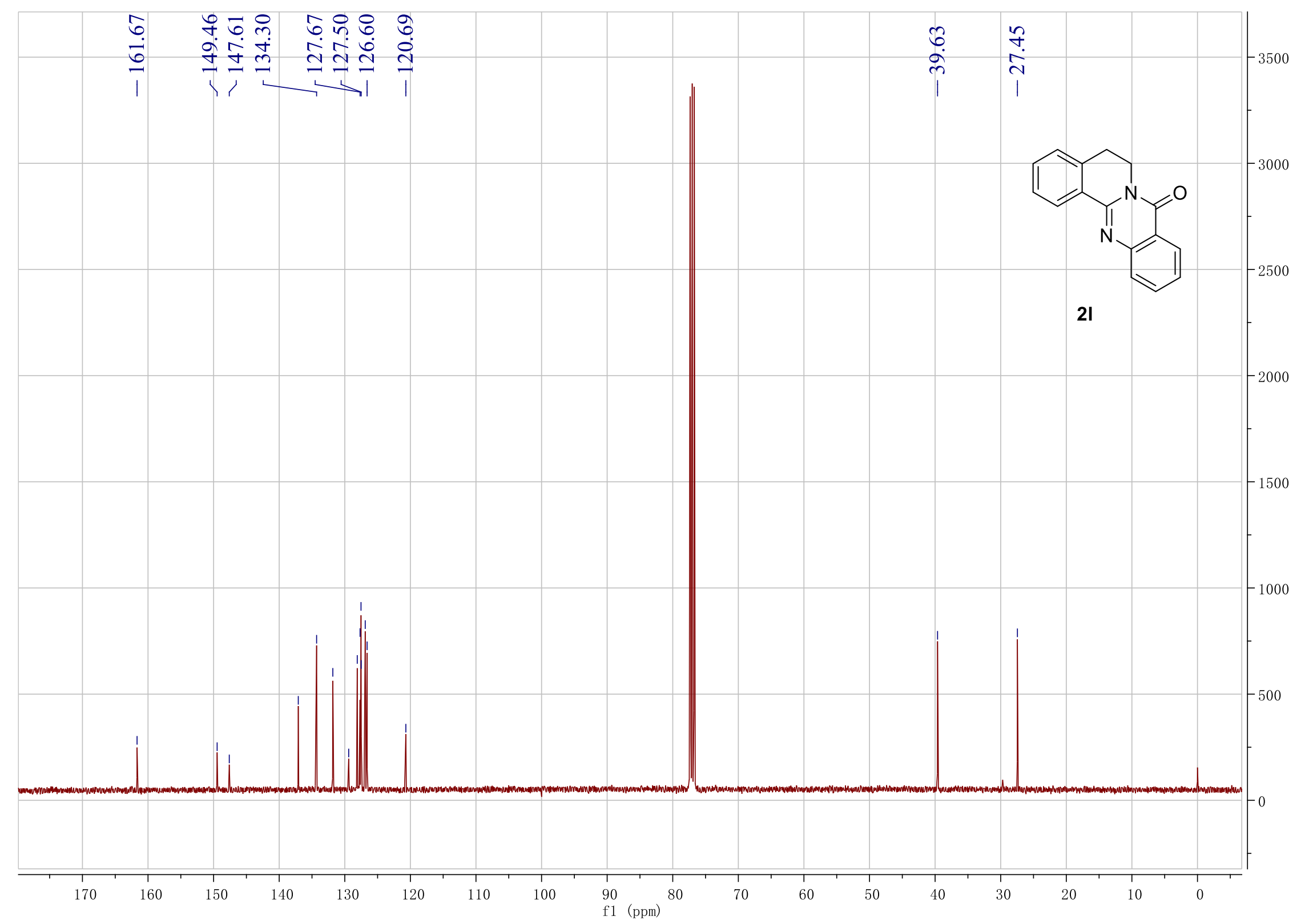




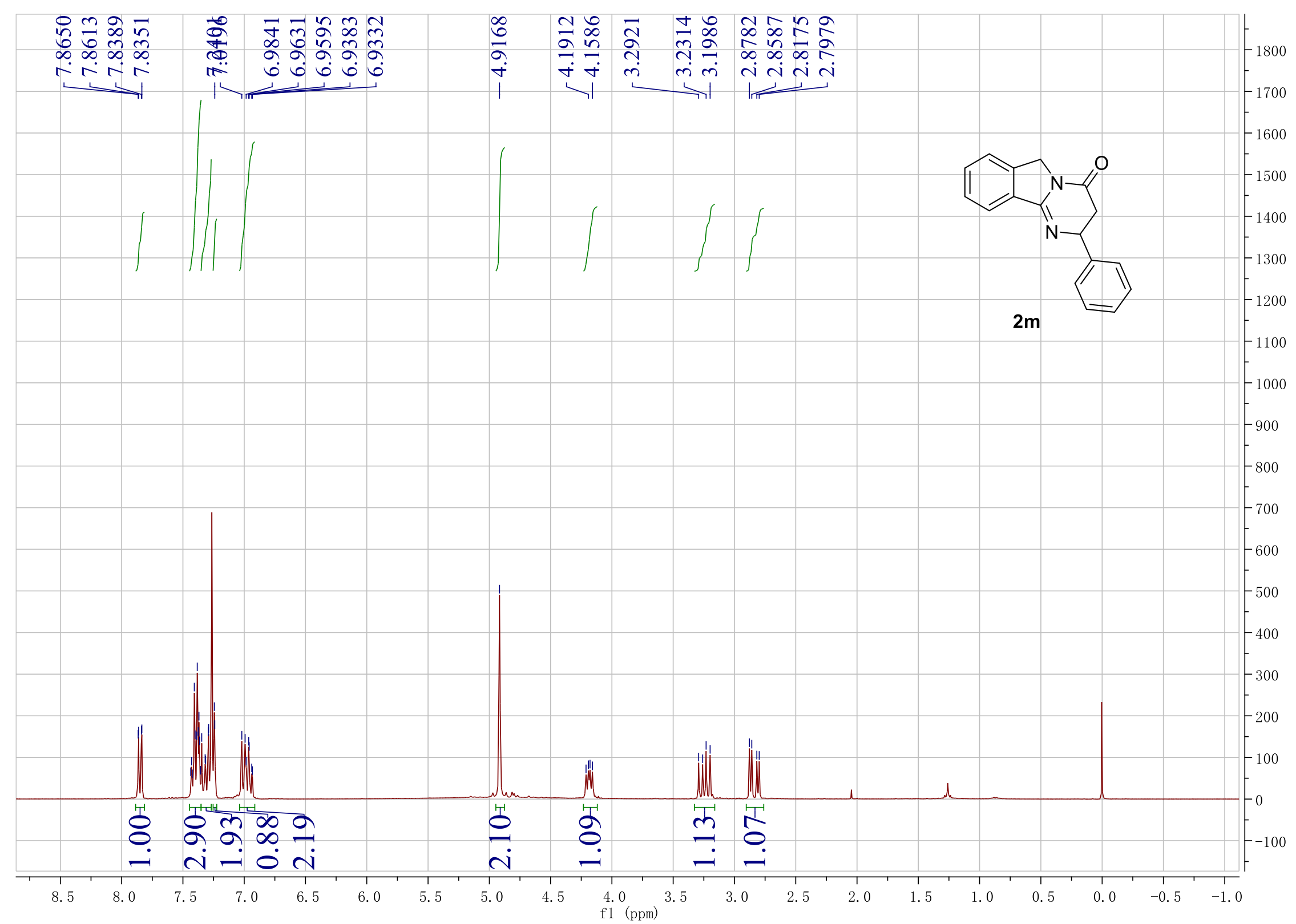




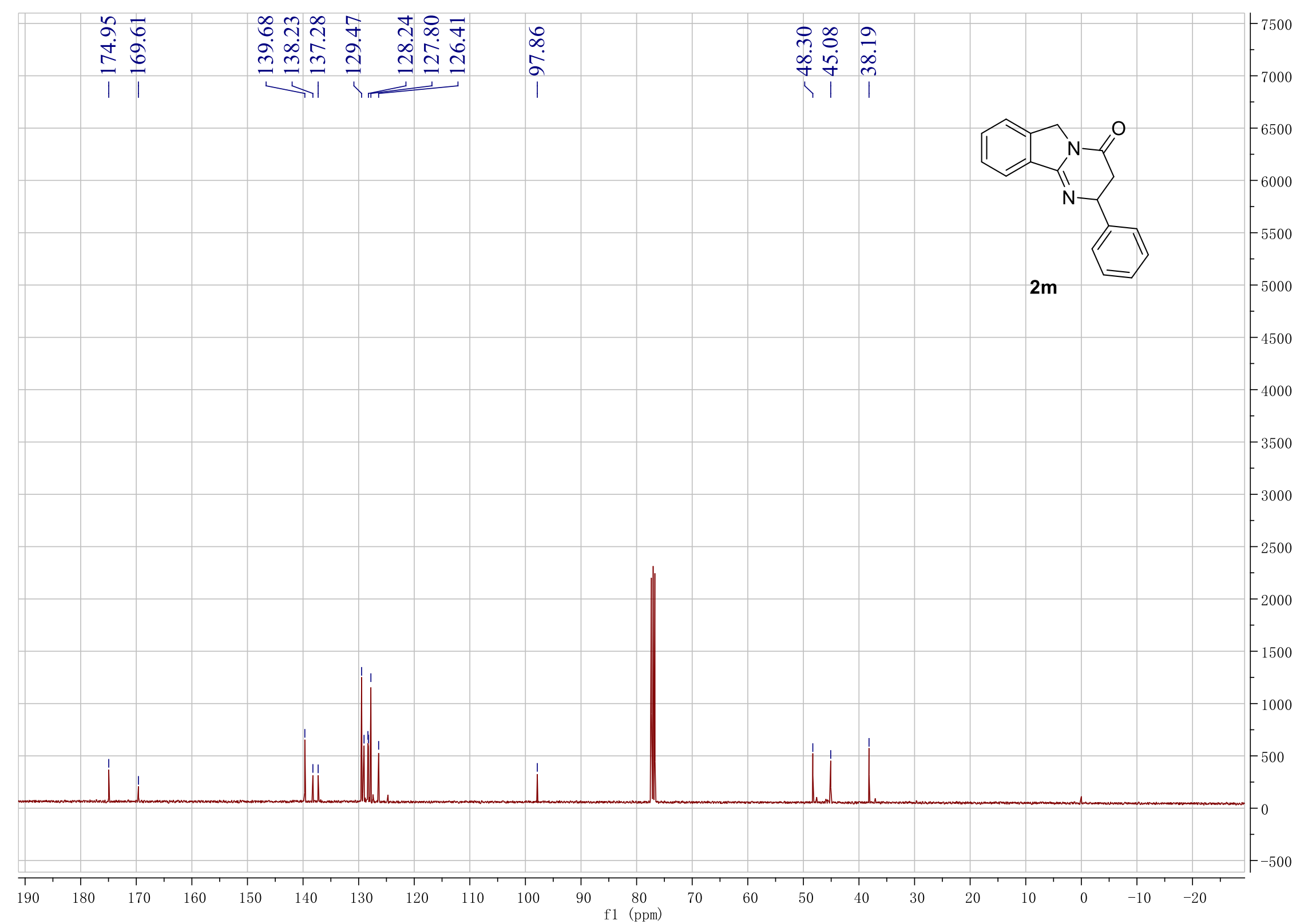




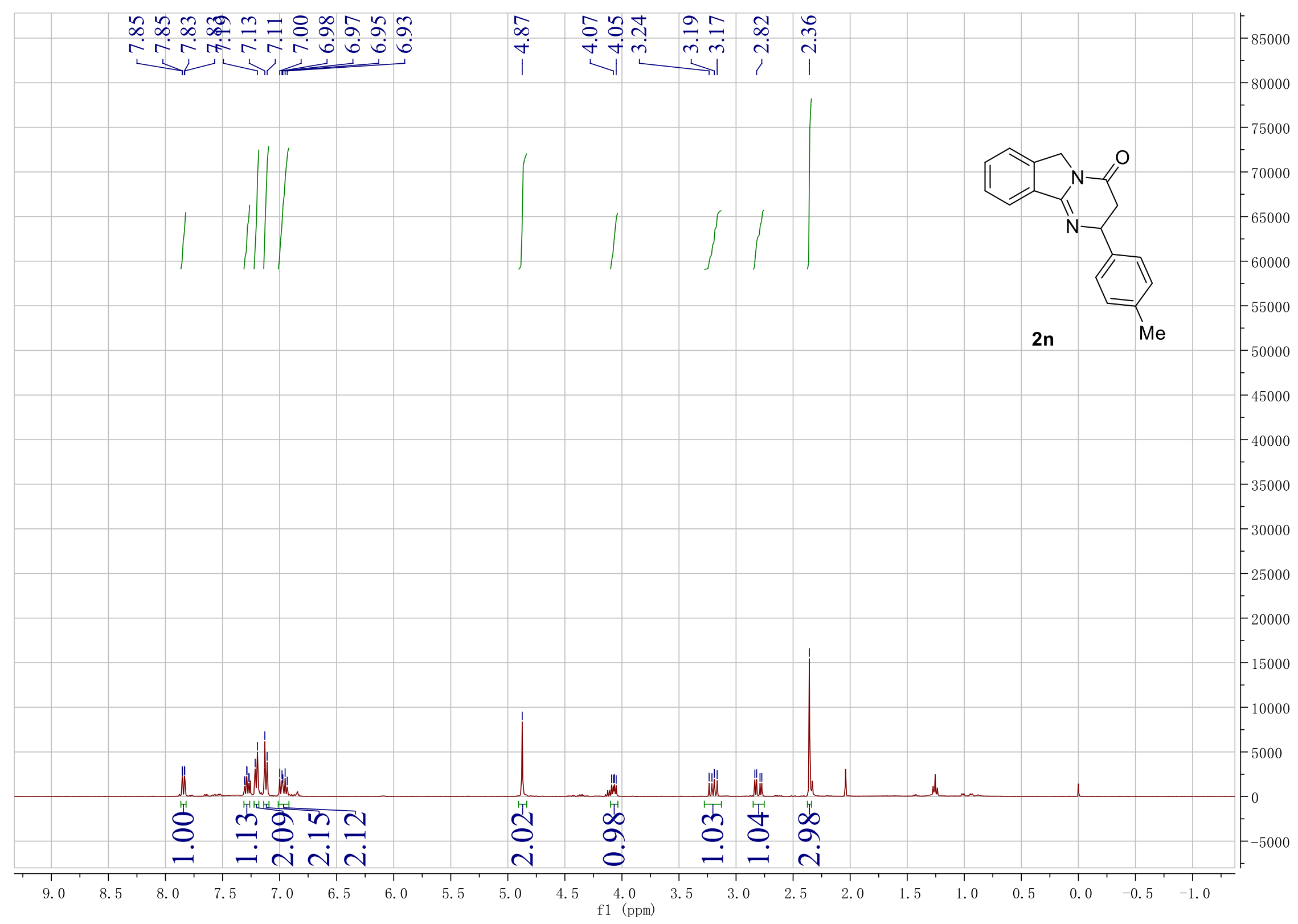




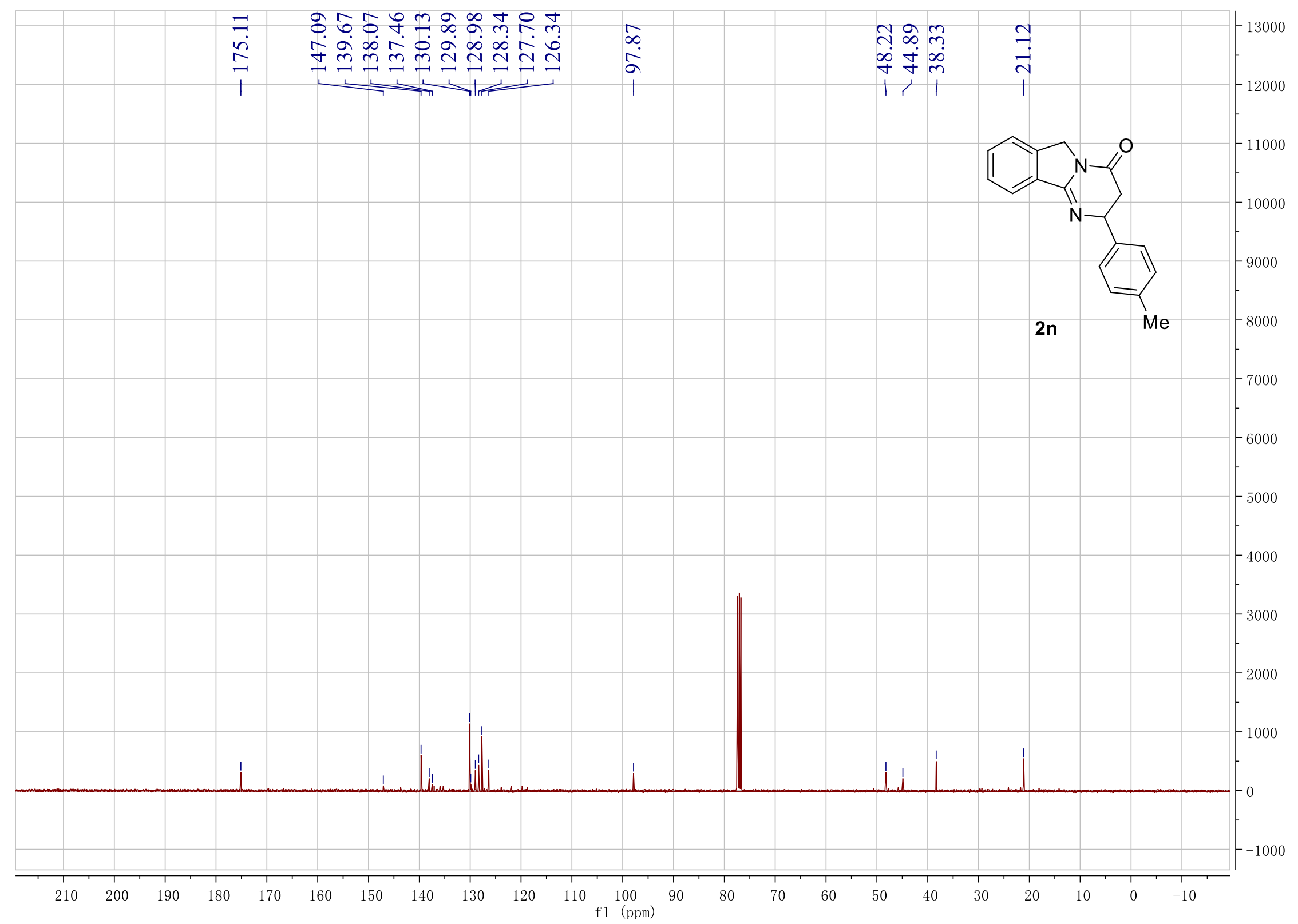




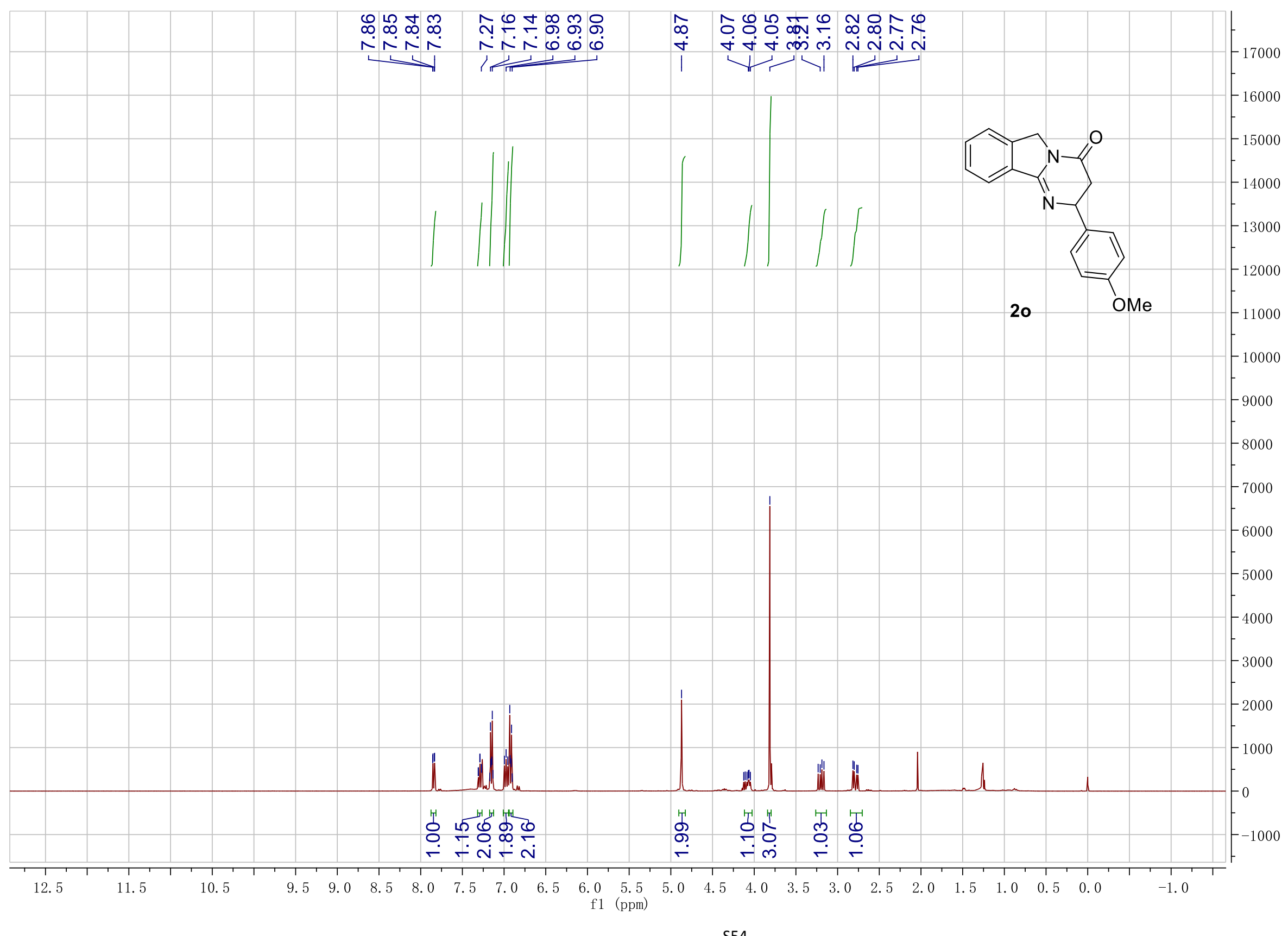




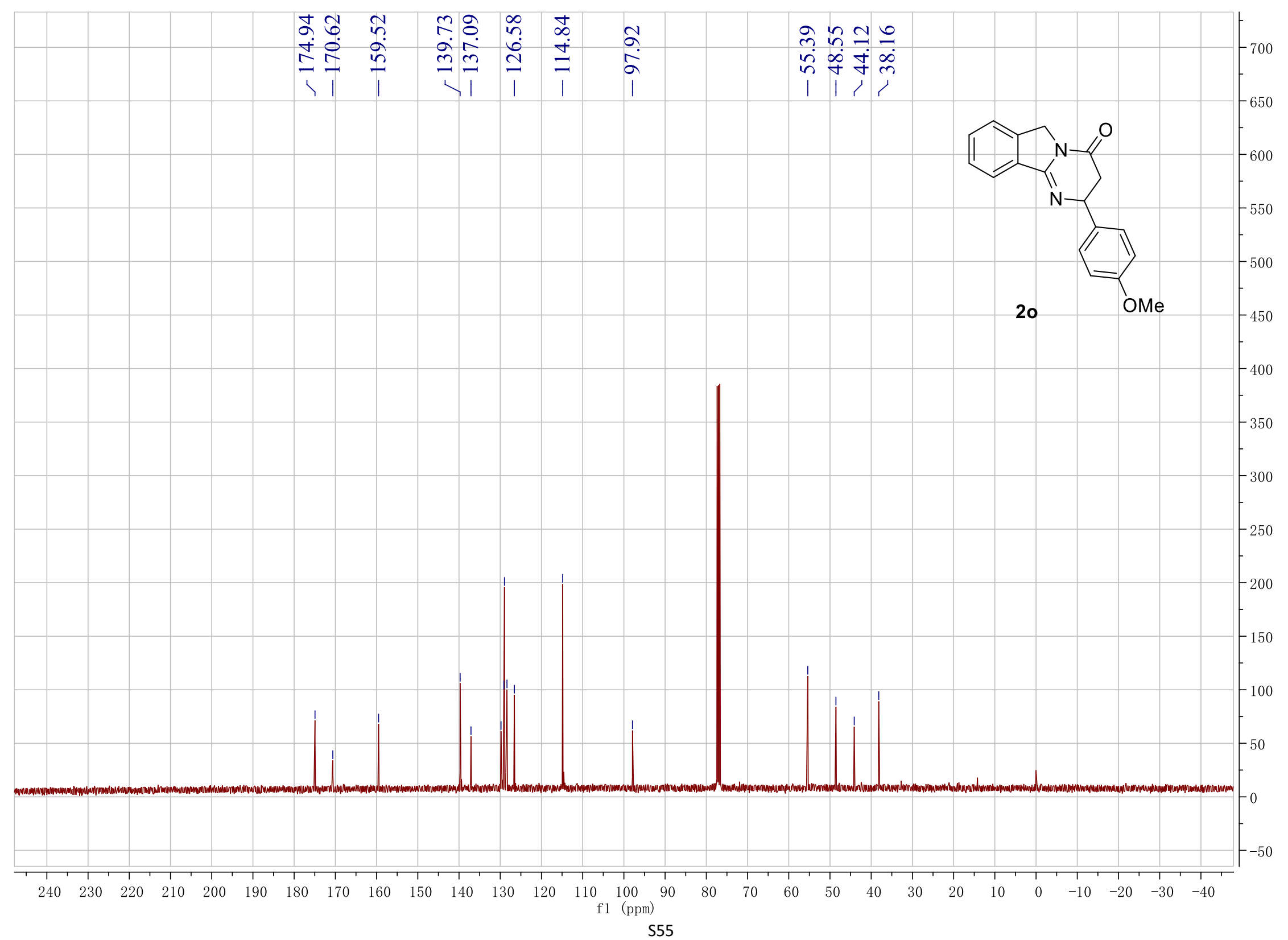

